\title{
Erratum to: Clinical Pharmacokinetics of Sacubitril/Valsartan (LCZ696): A Novel Angiotensin Receptor-Neprilysin Inhibitor
}

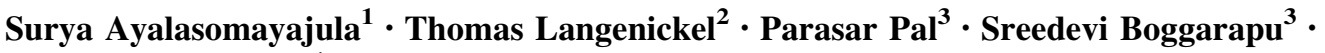 \\ Gangadhar Sunkara ${ }^{1}$
}

Published online: 19 May 2017

(C) Springer International Publishing Switzerland 2017

\begin{abstract}
Sacubitril/valsartan (LCZ696) is indicated for the treatment of heart failure with reduced ejection fraction. Absorption of sacubitril/valsartan and conversion of sacubitril (prodrug) to sacubitrilat (neprilysin inhibitor) was rapid with maximum plasma concentrations of sacubitril, sacubitrilat, and valsartan (angiotensin receptor blocker) reaching within $0.5,1.5-2.0$, and $2.0-3.0 \mathrm{~h}$, respectively. With a twofold increase in dose, an increase in the area under the plasma concentration-time curve was proportional for sacubitril, $\sim 1$.9-fold for sacubitrilat, and $\sim 1.7$-fold for valsartan in healthy subjects. Following multiple twice-daily administration, steady-state maximum plasma concentration was reached within
\end{abstract}

The in-text citations in the tables were misaligned with the references in the original article. The full article with all the corrections is republished here.

The online version of the original article can be found under doi: 10 . 1007/s40262-017-0543-3.

Surya Ayalasomayajula

spayala@gmail.com

1 Novartis Institutes for Biomedical Research, Clinical PKPD, East Hanover, NJ, USA

2 Novartis Institutes for Biomedical Research, Translational Medicine, Novartis Pharma AG, Basel, Switzerland

3 Novartis Healthcare Private Limited, Hyderabad, India
3 days, showing no accumulation for sacubitril and valsartan, while $\sim 1.6$-fold accumulation for sacubitrilat. Sacubitril is eliminated predominantly as sacubitrilat through the kidney; valsartan is eliminated mainly by biliary route. Drug-drug interactions of sacubitril/valsartan were evaluated with medications commonly used in patients with heart failure including furosemide, warfarin, digoxin, carvedilol, levonorgestrel/ethinyl estradiol combination, amlodipine, omeprazole, hydrochlorothiazide, intravenous nitrates, metformin, statins, and sildenafil. Co-administration with sacubitril/valsartan increased the maximum plasma concentration $(\sim 2.0$ fold) and area under the plasma concentration-time curve (1.3-fold) of atorvastatin; however, it did not affect the pharmacokinetics of simvastatin. Age, sex, or ethnicity did not affect the pharmacokinetics of sacubitril/valsartan. In patients with heart failure vs. healthy subjects, area under the plasma concentration-time curves of sacubitril, sacubitrilat, and valsartan were higher by approximately 1.6-, 2.1-, and 2.3-fold, respectively. Renal impairment had no significant impact on sacubitril and valsartan area under the plasma concentration-time curves, while the area under the plasma concentrationtime curve of sacubitrilat correlated with degree of renal function (1.3-, 2.3-, 2.9-, and 3.3-fold with mild, moderate, and severe renal impairment, and end-stage renal disease, respectively). Moderate hepatic impairment increased the area under the plasma concentration-time curves of valsartan and sacubitrilat $\sim 2$.1-fold.

Keywords Angiotensin receptor-neprilysin inhibitor . Drug-drug interaction - Pharmacokinetics .

Sacubitril/valsartan 


\section{Key Points}

Sacubitril/valsartan is a first-in-class ARNI approved to reduce the risk of cardiovascular death and HF hospitalization in patients with HFrEF (NYHA IIIV).

No significant accumulation of either sacubitril or valsartan was observed at the steady state. The majority of sacubitril (primarily as sacubitrilat) is excreted in urine and a majority of valsartan is excreted in feces.

No clinically relevant interactions were observed when sacubitril/valsartan was coadministered with digoxin, warfarin, HCTZ, amlodipine, omeprazole, metformin, carvedilol or a combination oral contraceptive.

Caution should be exercised when administering sacubitril/valsartan with statins, considering the $\sim$ twofold increase in the $\mathrm{C}_{\max }$ of atorvastatin (with no impact on AUC).

The AUC of sacubitrilat increased with increasing severity of renal impairment with no impact in patients with mild renal impairment and a 2.3, 2.9, and 3.3-fold higher in patients with moderate- and severe renal impairment, and end state renal disease without dialysis, respectively, compared with healthy subjects.

In patients with hepatic impairment, increases in the AUC and $\mathrm{C}_{\max }$ of sacubitril were not considered clinically relevant because it is an inactive prodrug, while the observed increase in the AUC of valsartan was consistent with its route of elimination.

\section{Introduction}

Chronic heart failure (HF) poses a significant global health burden with an estimated prevalence of $1-2 \%$ of adult populations of developed countries [1,2]. Neurohormonal pathways such as the renin-angiotensin-aldosterone system (RAAS) and the sympathetic nervous system play a critical role in the pathophysiology of HF, with initial compensatory and subsequent detrimental actions. Inhibition of RAAS with angiotensin-converting enzyme inhibitors or angiotensin receptor blockers in combination with $\beta$-blockers and mineralocorticoid receptor antagonists are established treatments for chronic HF [3-9]. However, despite the considerable therapeutic advances in the treatment of HF in the past two decades, the 5-year mortality of HF remains (50\%) [10].
Natriuretic peptides (NPs), through activation of membrane-bound NP receptors and their second messenger cyclic guanosine monophosphate (cGMP), mediate beneficial cardio-renal effects such as natriuresis, diuresis, vasodilatation, inhibition of RAAS, sympathetic nervous system, and aldosterone secretion [11]. Despite their upregulation in HF, NPs do not fully compensate the activation of RAAS and sympathetic nervous system, potentially owing to a deficiency of biologically active peptides [12-14]. Enhancing the biological activity of NPs, particularly in conjunction with RAAS blockade can provide therapeutic benefits [15]. Angiotensin receptorneprilysin inhibition is a novel therapeutic concept based on enhancing the availability of biologically active NPs by inhibiting their degradation by neprilysin, while simultaneously blocking the deleterious effects of sustained RAAS activation [16].

Sacubitril/valsartan (LCZ696), a first-in-class angiotensin receptor-neprilysin inhibitor, provides simultaneous neprilysin inhibition and angiotensin receptor blockade. Compared with enalapril, in patients with HF and reduced ejection fraction (HFrEF), treatment with sacubitril/valsartan resulted in a superior reduction in the risk of cardiovascular death (20\%), HF hospitalization (20\%), and death from any cause $(16 \%)$ and provided other benefits $[17,18]$. Considering these beneficial effects, sacubitril/valsartan has been approved in $>60$ countries for the treatment of HFrEF and is recommended by European and American HF guidelines [1, 19] for the treatment of chronic symptomatic HFrEF (New York Heart Association Class II-IV). The beneficial effects of sacubitril/valsartan on clinical outcomes are currently being studied in patients with HF and preserved ejection fraction (HFpEF; PARAGON-HF trial; Clinical Trial Registry: NCT01920711) [20]; in post-myocardial infarction (PARADISE-MI trial; Clinical Trial Registry: NCT02678312); and in pediatric patients with HFrEF (Clinical Trial Registry: NCT02678312). The present review summarizes the clinical pharmacokinetics of sacubitril/valsartan following oral single- and multiple-dose administrations in healthy subjects and in patients with HF. Furthermore, the drug-drug interaction potential and the impact of age, sex, race, ethnicity, and renal or hepatic impairment on the pharmacokinetics of sacubitril/valsartan are described.

\section{Physicochemical Properties of Sacubitril/ Valsartan}

Sacubitril/valsartan is a sodium salt complex of anionic forms of sacubitril (an inactive prodrug of the active neprilysin inhibitor, sacubitrilat) and valsartan (an angiotensin receptor blocker) in a 1:1 molar ratio [21, 22]. The 
sacubitril/valsartan 50-mg dose contains $24 \mathrm{mg}$ of sacubitril and $26 \mathrm{mg}$ of valsartan; the $100-\mathrm{mg}$ dose contains $49 \mathrm{mg}$ of sacubitril and $51 \mathrm{mg}$ of valsartan, and the 200-mg dose contains $97 \mathrm{mg}$ of sacubitril and $103 \mathrm{mg}$ of valsartan. Upon oral administration, sacubitril/valsartan provides systemic exposure to sacubitril, sacubitrilat, and valsartan.

Sacubitril/valsartan is highly soluble in water $(100 \mathrm{mg} /$ $\mathrm{mL}$ ) [23]. In-vitro permeability assays using Caco-2 cell monolayers showed a moderate-to-high permeability of sacubitril with an effective permeability coefficient of $>50 \times 10^{-5} \mathrm{~cm} / \mathrm{min}$ [24]. Sacubitril exhibits P-glycoprotein (P-gp)-mediated efflux [25]. Although no study has been conducted to determine the impact of P-gp inhibition on the bioavailability of sacubitril, the impact is expected to be minimal considering high permeability and bioavailability $(>60 \%)$ of sacubitril. Valsartan is categorized as a class III drug according to the biopharmaceutical classification system, known to exhibit low permeability, high solubility, and poor metabolism [26].

\section{Clinical Pharmacokinetics}

\subsection{Single- and Multiple-Dose Pharmacokinetics in Healthy Subjects}

Pharmacokinetic data of sacubitril/valsartan following administration of single ascending doses of 5-1200 mg were pooled from 11 clinical pharmacology studies conducted in healthy adults (Table 1). Following oral administration, sacubitril and valsartan were rapidly absorbed reaching maximum plasma concentration $\left(\mathrm{C}_{\max }\right)$ within the median time [time to maximum plasma concentration $\left(\mathrm{T}_{\max }\right)$; range represents data from different studies] of 0.5 and $1.5-2.0 \mathrm{~h}$, respectively. The conversion of sacubitril to sacubitrilat was also rapid, with a median $\mathrm{T}_{\max }$ of 2.0-3.0 h for sacubitrilat. Increasing dose did not impact the $\mathrm{T}_{\max }$ of all analytes. A pooled analysis of single-dose pharmacokinetics following administration of 200 and $400 \mathrm{mg}$ of sacubitril/valsartan (representative doses) is presented in Table 2 and the representative area under the plasma concentration-time curves (AUCs) are presented in Fig. 1. With twofold increase in the dose within the evaluated dose range, the increase in the AUC was dose proportional for sacubitril, $\sim 1.9$-fold for sacubitrilat, and $\sim 1$.7-fold for valsartan. Following single-dose administration, the absolute oral bioavailability was estimated as $60 \%$ for sacubitril [27]. The absolute oral bioavailability of valsartan delivered by sacubitril/valsartan was approximately $60 \%$ higher than the $23 \%$ bioavailability reported for other marketed formulations of valsartan when administered alone $[27,28]$. The 200-mg dose of sacubitril/valsartan containing $103 \mathrm{mg}$ of valsartan provided systemic exposure of valsartan similar to that following administration of $160 \mathrm{mg}$ of valsartan in alternate marketed formulations. The single ascending dose pharmacokinetics of sacubitril/valsartan in healthy subjects from this pooled analysis is consistent with previously reported pharmacokinetic data [21].

Upon multiple-dose administration, all analytes of sacubitril/valsartan reached steady-state plasma concentrations within 3 days of once-daily (QD) or twice-daily (BID) administration [25, 29]. The steady-state pharmacokinetic assessments of sacubitril/valsartan (50-900 mg QD) showed a rapid absorption of sacubitril and valsartan similar to single-dose administrations with a $\mathrm{T}_{\max }$ of 0.6-0.9 and 1.6-4.9 h, respectively [21]. In addition, sacubitrilat levels increased rapidly with a $\mathrm{T}_{\max }$ of 1.8-2.7 h, suggesting rapid conversion of sacubitril. No significant accumulation of either sacubitril or valsartan was observed at any dose level of sacubitril/valsartan following QD administration. Minimal accumulation of sacubitrilat $(\mathrm{R}=1.2)$ was observed in all dose groups of sacubitril/valsartan. The inter-subject variability (coefficient of variation) of pharmacokinetic parameters was estimated to be $20-39 \%$ for sacubitril, $11-26 \%$ for sacubitrilat, and $17-58 \%$ for valsartan [21].

The accumulation of analytes of sacubitril/valsartan following multiple twice-daily administration of the 200-mg dose pooled from five studies (Table 2) was consistent with that reported in a previous study [29], wherein no significant accumulation of sacubitril and valsartan (1.3fold) was observed, while a 1.6-fold accumulation was observed for sacubitrilat.

\subsection{Effect of Food}

The effect of food on the pharmacokinetics of all the analytes (Table 3) was evaluated in healthy subjects following administrations of sacubitril/valsartan $400 \mathrm{mg}$ with a low-fat meal (500-600 kcal) and a high-fat meal (800-1000 kcal) [24] and $200 \mathrm{mg}$ of sacubitril/valsartan with a Japanese meal ( $\sim 500 \mathrm{kcal}, 14 \%$ fat) [30]. Administration of sacubitril/valsartan with food resulted in a decreased rate of absorption of sacubitril, as indicated by a delayed $\mathrm{T}_{\max }$ (by 1-2 $\mathrm{h}$ ) and a decreased $\mathrm{C}_{\max }$ (by 48-72\%). Consequently, the rate of appearance of its active metabolite sacubitrilat in plasma was delayed and the $\mathrm{C}_{\max }$ was decreased (by 19-28\%). However, no marked changes were observed in the AUC of sacubitrilat, indicating no clinical relevance of the decreased $\mathrm{C}_{\max }$ of sacubitril (in-active prodrug) under fed conditions. Conversely, for valsartan, a significant decrease was observed in the $\mathrm{C}_{\max }$ (by 39-51\%) and AUC (by 34-40\%; except when administered with a high-fat meals, which resulted in only a $9 \%$ decrease); these 
Table 1 Summary of clinical trials conducted to study pharmacokinetics of sacubitril/valsartan

\begin{tabular}{|c|c|c|c|c|}
\hline References & $\mathrm{N}$ & Objective & Dose/frequency & Population \\
\hline \multicolumn{5}{|c|}{ Single dose pharmacokinetics of sacubitril/valsartan 5-1200 mg dose range in healthy subjects } \\
\hline Akahori et al. [30] ${ }^{\mathrm{a}}$ & 40 & $\begin{array}{l}\text { Single ascending dose study assessing } \\
\text { safety and tolerability and PK of } \\
\text { sacubitril/valsartan }\end{array}$ & $\begin{array}{l}\text { Single doses } \\
\text { Sacubitril/valsartan 20,80, 200, 400, and } \\
\quad 600 \mathrm{mg} \\
\text { Placebo }\end{array}$ & $\begin{array}{l}\text { Healthy subjects } \\
\text { (Japanese) }\end{array}$ \\
\hline Gu et al. [21] & 25 & $\begin{array}{l}\text { Single ascending dose assessing PK, } \\
\text { safety and tolerability of } \\
\text { sacubitril/valsartan vs valsartan }\end{array}$ & $\begin{array}{l}\text { Single doses } \\
\text { Sacubitril/valsartan } 5,20,80 \mathrm{mg} \\
\text { Valsartan } 40 \mathrm{mg}\end{array}$ & Healthy subjects \\
\hline Gu et al. $[21]^{\mathrm{a}}$ & 65 & $\begin{array}{l}\text { Single and multiple ascending dose } \\
\text { study assessing safety and tolerability; } \\
\text { PK and PD of sacubitril/valsartan }\end{array}$ & $\begin{array}{l}\text { Single doses } \\
\text { Sacubitril/valsartan 200,600, 900, and } \\
1200 \mathrm{mg} \\
\text { Multiple doses } \\
\text { Sacubitril/valsartan 50, 200,600, and } 900 \mathrm{mg} \\
\text { QD for } 14 \text { days } \\
\text { Placebo }\end{array}$ & Healthy subjects \\
\hline Gu et al. [21] & 53 & $\begin{array}{l}\text { Relative bioavailability of valsartan } \\
\text { from sacubitril/valsartan versus } \\
\text { valsartan marketed formulation }\end{array}$ & $\begin{array}{l}\text { Single doses } \\
\text { Sacubitril/valsartan } 400 \mathrm{mg} \\
\text { Valsartan } 320 \mathrm{mg}\end{array}$ & Healthy subjects \\
\hline $\begin{array}{l}\text { Ayalasomayajula } \\
\text { et al. [24] }\end{array}$ & 36 & $\begin{array}{l}\text { Effect of food on the PK of } \\
\text { sacubitril/valsartan }\end{array}$ & $\begin{array}{l}\text { Single dose } \\
\text { Sacubitril/valsartan } 400 \mathrm{mg}\end{array}$ & Healthy subjects \\
\hline Gan et al. [94] & 36 & $\begin{array}{l}\text { Effect of age and gender on } \\
\text { sacubitril/valsartan }\end{array}$ & $\begin{array}{l}\text { Single dose } \\
\text { Sacubitril/valsartan } 400 \mathrm{mg}\end{array}$ & Healthy subjects \\
\hline Gan et al. [49] & 28 & PK interaction with omeprazole & $\begin{array}{l}\text { Multiple doses once-daily } \\
\text { Sacubitril/valsartan } 400 \mathrm{mg} \\
\text { Omeprazole } 40 \mathrm{mg}\end{array}$ & Healthy subjects \\
\hline Han et al. $[100]^{\mathrm{a}}$ & 40 & $\begin{array}{l}\text { Single ascending dose study of } \\
\text { sacubitril/valsartan in Chinese } \\
\text { population }\end{array}$ & $\begin{array}{l}\text { Single doses } \\
\text { Sacubitril/valsartan 50,100, 200, } 400 \mathrm{mg}\end{array}$ & $\begin{array}{l}\text { Healthy subjects } \\
\text { (Chinese) }\end{array}$ \\
\hline $\begin{array}{l}\text { Langenickel et al. } \\
\text { [101] }\end{array}$ & 83 & Thorough QTc study & $\begin{array}{l}\text { Single doses } \\
\text { Sacubitril/valsartan } 400 \text { and } 1200 \mathrm{mg} \text {; } \\
\text { moxifloxacin } 400 \mathrm{mg} \text {; placebo }\end{array}$ & Healthy subjects \\
\hline CLCZ696B2126 & 40 & $\begin{array}{l}\text { Relative bioavailability of } \\
\text { sacubitril/valsartan minitablets and } \\
\text { effect of food on the PK of } \\
\text { sacubitril/valsartan minitablets }\end{array}$ & $\begin{array}{l}\text { Single doses } \\
\text { Sacubitril/valsartan } 200 \mathrm{mg} \text { FMI and } \\
\text { minitablets }\end{array}$ & Healthy subjects \\
\hline $\begin{array}{l}\text { Kulmatycki et al. } \\
{[45]^{\mathrm{a}}}\end{array}$ & 32 & $\begin{array}{l}\text { Effect of hepatic impairment on } \\
\text { sacubitril/valsartan PK }\end{array}$ & $\begin{array}{l}\text { Single dose } \\
\text { Sacubitril/valsartan } 200 \mathrm{mg}\end{array}$ & $\begin{array}{l}\text { Patients with } \\
\text { mild/moderate hepatic } \\
\text { impairment and } \\
\text { matched healthy } \\
\text { subjects }\end{array}$ \\
\hline \multicolumn{5}{|c|}{ Steady-state pharmacokinetics of sacubitril valsartan $200 \mathrm{mg}$ BID and $400 \mathrm{mg}$ QD in healthy subjects } \\
\hline $\begin{array}{l}\text { Ayalasomayajula } \\
\text { et al. [29] }\end{array}$ & 28 & PK interaction with atorvastatin & $\begin{array}{l}\text { Multiple doses } \\
\text { Sacubitril/valsartan } 200 \mathrm{mg} \text { BID } \\
\text { Atorvastatin } 80 \mathrm{mg} \text { QD }\end{array}$ & Healthy Chinese subjects \\
\hline $\begin{array}{l}\text { Ayalasomayajula } \\
\text { et al. (Submitted) }\end{array}$ & 28 & PK and PD interaction with furosemide & $\begin{array}{l}\text { Multiple doses of sacubitril/valsartan } 200 \mathrm{mg} \\
\text { BID } \\
\text { Single dose of furosemide } 40 \mathrm{mg}\end{array}$ & Healthy subjects \\
\hline $\begin{array}{l}\text { Ayalasomayajula } \\
\text { et al. [25] }\end{array}$ & 24 & PK interaction with digoxin & $\begin{array}{l}\text { Multiple doses } \\
\text { Sacubitril/valsartan } 200 \mathrm{mg} \text { BID } \\
\text { Digoxin } 0.25 \mathrm{mg} \text { QD }\end{array}$ & Healthy subjects \\
\hline
\end{tabular}


Table 1 continued

\begin{tabular}{|c|c|c|c|c|}
\hline References & $\mathrm{N}$ & Objective & Dose/frequency & Population \\
\hline $\begin{array}{l}\text { Ayalasomayajula } \\
\text { et al. [25] }\end{array}$ & 25 & PK and PD interactions with warfarin & $\begin{array}{l}\text { Multiple doses of sacubitril/valsartan } 200 \mathrm{mg} \\
\text { BID } \\
\text { Single dose } \\
\text { Warfarin sodium } 25 \mathrm{mg}\end{array}$ & Healthy subjects \\
\hline $\begin{array}{l}\text { Schuehly et al. } \\
\text { (submitted; } \\
\text { EudraCT no. } \\
\text { 2013-001783-36) }\end{array}$ & 39 & $\begin{array}{l}\text { PD interaction with intravenous } \\
\text { nitroglycerin }\end{array}$ & $\begin{array}{l}\text { Multiple doses of sacubitril/valsartan } 200 \mathrm{mg} \\
\text { BID } \\
\text { Nitroglycerin infusion up to } 40 \mu \mathrm{g} / \mathrm{min} \\
\text { matching placebo }\end{array}$ & Healthy subjects \\
\hline Hsiao et al. [48] $]^{\mathrm{b}}$ & 28 & PK interaction with amlodipine & $\begin{array}{l}\text { Multiple once daily doses } \\
\text { Sacubitril/valsartan } 400 \mathrm{mg} \\
\text { Amlodipine } 10 \mathrm{mg}\end{array}$ & Healthy subjects \\
\hline \multicolumn{5}{|c|}{ Impact of body weight and BMI on pharmacokinetics of sacubitril/valsartan in healthy subjects ${ }^{b}$} \\
\hline Gan et al. [49] & 26 & PK interaction with metformin & $\begin{array}{l}\text { Multiple once daily doses } \\
\text { Sacubitril/valsartan } 400 \mathrm{mg} \\
\text { Metformin } 1000 \mathrm{mg}\end{array}$ & $\begin{array}{l}\text { Healthy Japanese } \\
\text { subjects }\end{array}$ \\
\hline Hsiao et al. [48] & 28 & PK interaction with carvedilol & $\begin{array}{l}\text { Multiple doses } \\
\text { Sacubitril/valsartan } 400 \mathrm{mg} \text { QD } \\
\text { Carvedilol } 12.5 \text { and } 25 \mathrm{mg} \text { (titration) BID }\end{array}$ & Healthy subjects \\
\hline Hsiao et al. [48] & 28 & PK interaction with $\mathrm{HCTZ}$ & $\begin{array}{l}\text { Multiple once daily doses } \\
\text { Sacubitril/valsartan } 400 \mathrm{mg} \\
\text { HCTZ } 25 \mathrm{mg}\end{array}$ & Healthy subjects \\
\hline \multicolumn{5}{|c|}{ Pharmacokinetics of sacubitril/valsartan in patients } \\
\hline $\begin{array}{l}\text { Kobalava et al. } \\
\text { [38] }\end{array}$ & 30 & $\begin{array}{l}\text { Multiple dose study assessing safety, } \\
\text { tolerability, PK and PD of } \\
\text { sacubitril/valsartan }\end{array}$ & $\begin{array}{l}\text { Sacubitril/valsartan 7-day dose titration with } \\
100 \mathrm{mg} \text { bid followed by } 200 \mathrm{mg} \text { bid for } \\
14 \text { days (optional start of dose titration with } \\
\text { sacubitril } 50 \mathrm{mg} \text { was not utilized) }\end{array}$ & $\begin{array}{l}\text { Patients with stable CHF } \\
\text { (NYHA II-IV) }\end{array}$ \\
\hline NCT01353508 & 16 & $\begin{array}{l}\text { Effect of sacubitril/valsartan versus } \\
\text { valsartan on natriuresis in patients } \\
\text { with HF and hypertension }\end{array}$ & $\begin{array}{l}\text { Multiple once daily doses } \\
\text { Sacubitril/valsartan } 400 \mathrm{mg} \\
\text { Valsartan } 320 \mathrm{mg}\end{array}$ & Patient with stable CHF \\
\hline \multicolumn{5}{|c|}{ Regression analysis of impact of body weight on pharmacokinetics of sacubitril/valsartan } \\
\hline Ito et al. [93] & 32 & $\begin{array}{l}\text { Safety, tolerability and efficacy of } \\
\text { sacubitril/valsartan in Japanese } \\
\text { hypertensive patients with renal } \\
\text { dysfunction }\end{array}$ & $\begin{array}{l}\text { Multiple once daily doses } \\
\text { Sacubitril/valsartan 100, } 200 \text { and } 400 \mathrm{mg} \\
\text { Placebo }\end{array}$ & $\begin{array}{l}\text { Japanese hypertensive } \\
\text { patients with renal } \\
\text { dysfunction }\end{array}$ \\
\hline Rakugi et al. [92] & 387 & $\begin{array}{l}\text { Efficacy and safety of } \\
\text { sacubitril/valsartan compared to } \\
\text { olmesartan in Japanese patients with } \\
\text { essential hypertension }\end{array}$ & $\begin{array}{l}\text { Sacubitril/valsartan } 200 \mathrm{mg} \text { QD for } 1 \text { week, } \\
\text { up-titrated to } 400 \mathrm{mg} \text { QD for } 7 \text { weeks } \\
\text { Olmesartan } 20 \mathrm{mg} \text { QD for } 8 \text { weeks } \\
\text { Placebo }\end{array}$ & $\begin{array}{l}\text { Japanese patients with } \\
\text { mild-to-moderate } \\
\text { essential hypertension }\end{array}$ \\
\hline
\end{tabular}

$B I D$ twice daily, $B M I$ body mass index, $H C T Z$ hydrochlorothiazide, $P D$ pharmacodynamics, $P K$ pharmacokinetics, $Q D$ once daily

a Studies included in analyzing the impact of race and ethnicity

b Hsiao et al. [48] (included in single ascending dose pharmacokinetics) is also included in analyzing the impact of body weight

changes in exposure (AUC) to valsartan in the presence of food are consistent with previous reports, wherein the pharmacokinetics of valsartan was similar under fed and fasting conditions [31, 32]. In addition, efficacy and safety were established in the phase III PARADIGM-HF trial [17], wherein sacubitril/valsartan was administered regardless of food intake. Overall, the effect of food on the pharmacokinetics of sacubitril/valsartan is consistent irrespective of the doses (200 or $400 \mathrm{mg}$ ) administered, and food intake is not expected to alter its pharmacodynamics. Therefore, sacubitril/valsartan can be administered without regard to meals. 


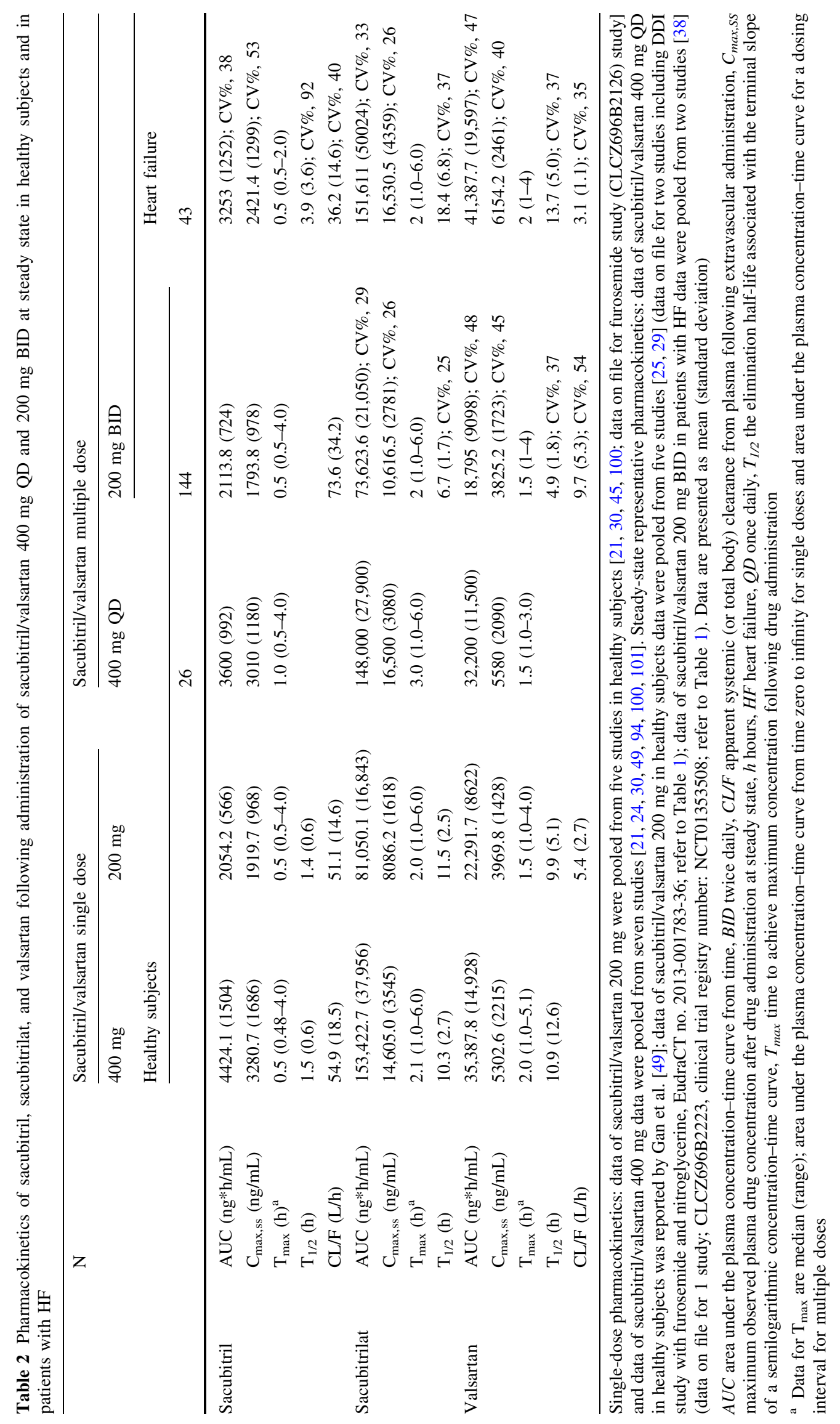


a

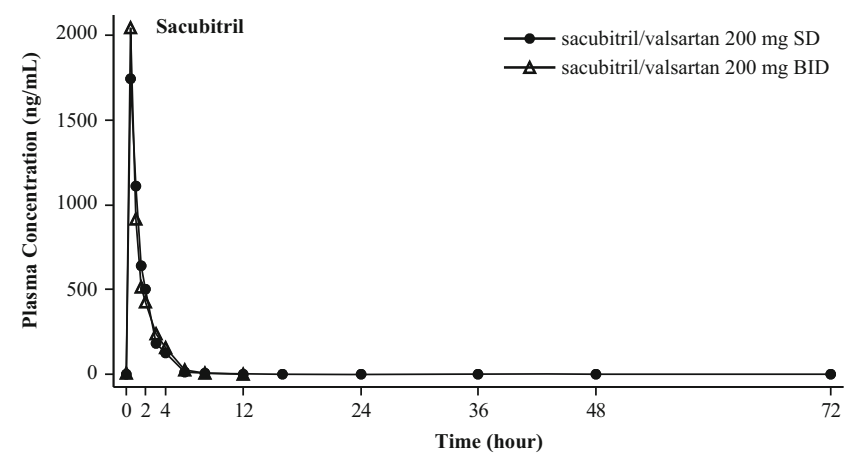

c

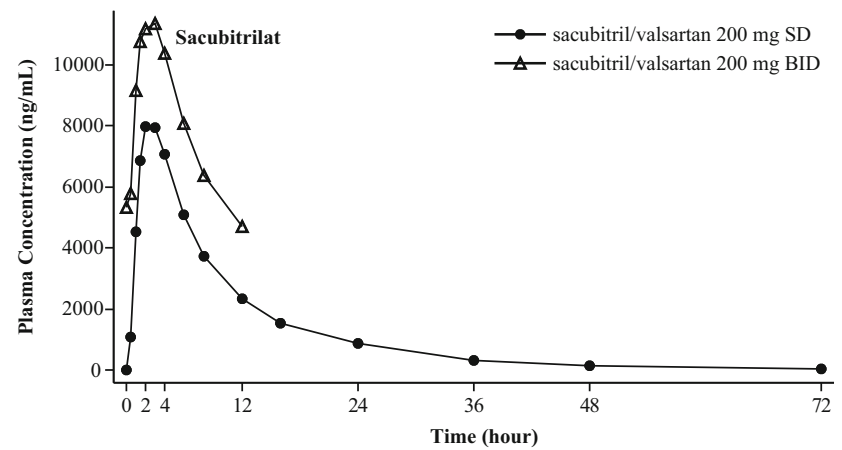

e

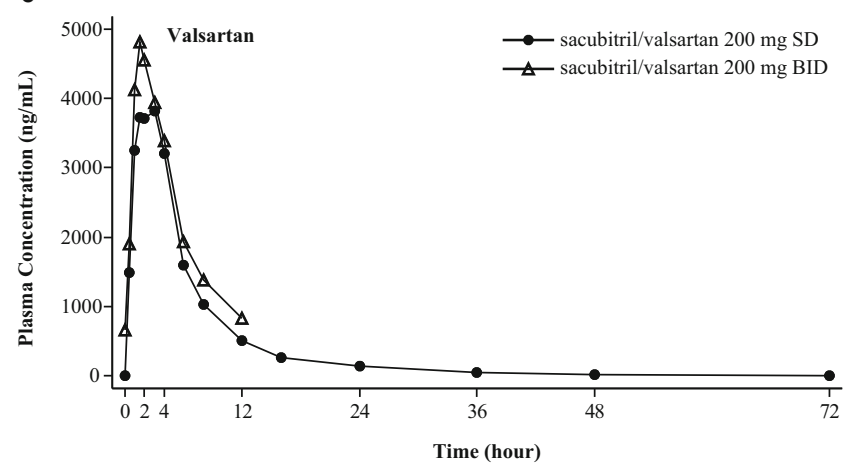

b

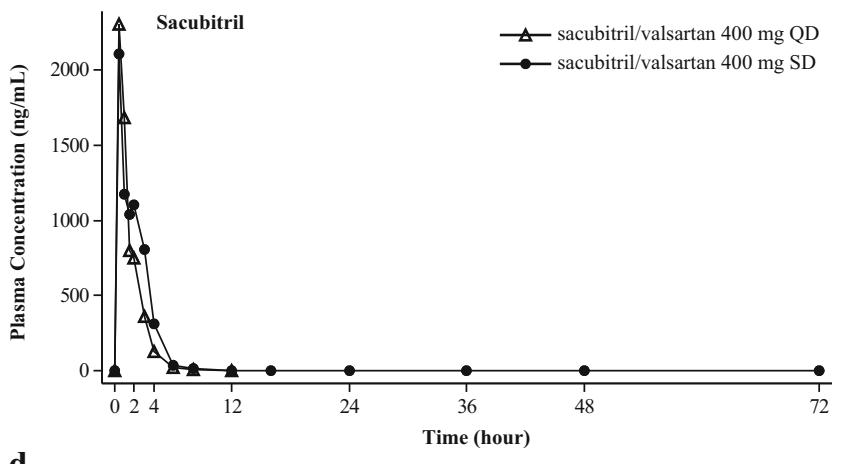

d
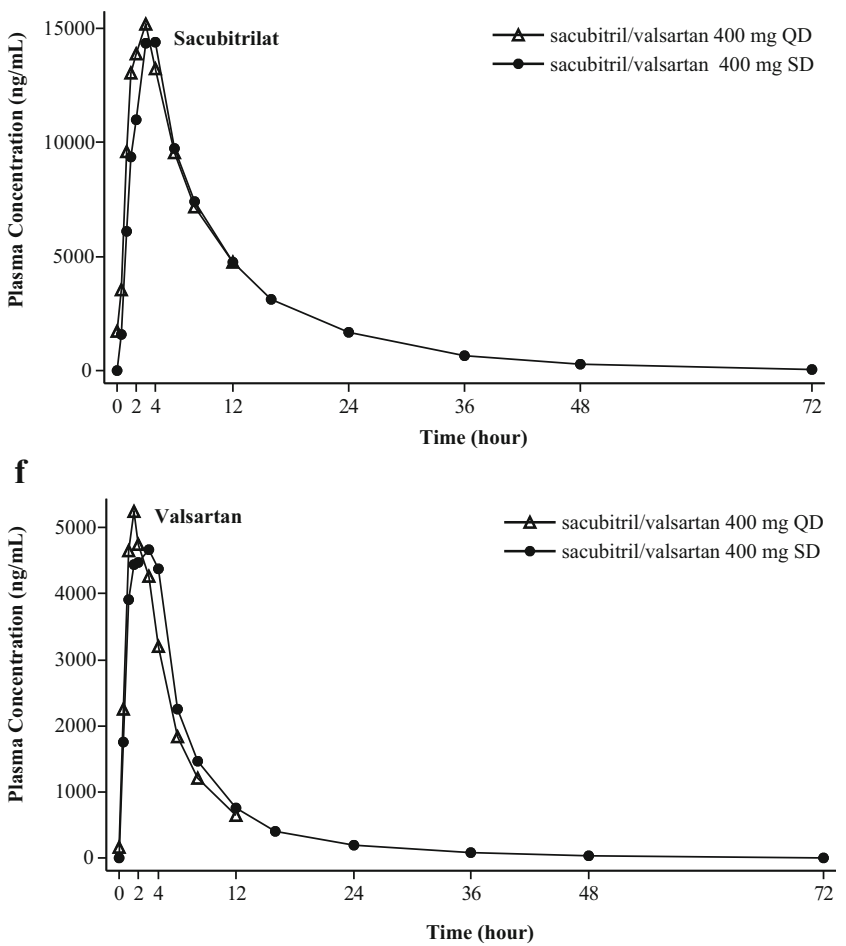

Fig. 1 Single- and multiple-dose pharmacokinetic profiles of sacubitril, sacubitrilat, and valsartan in healthy subjects following administration of sacubitril/valsartan. $B I D$ twice daily, $Q D$ once daily, $S D$ single dose

\subsection{Distribution and Protein Binding}

Human plasma protein binding was characterized in vitro for sacubitril, sacubitrilat, and valsartan. Over a concentration range of $0.02-100 \mu \mathrm{g} / \mathrm{mL}$, protein binding for both sacubitril and sacubitrilat was $97 \%$ [27]. Protein binding of valsartan was also high (96\%) in human serum at concentrations ranging from 0.05 to $5 \mu \mathrm{g} / \mathrm{mL}$ [33]. Sacubitrilat crosses the blood-brain barrier to a very limited extent $(0.28 \%)$ [34]. The average apparent volumes of distribution of valsartan and sacubitril are 75 and 103 L, respectively [27].

\subsection{Metabolism}

Sacubitril/valsartan analytes do not undergo significant metabolism by cytochrome P450 (CYP) isozymes; sacubitril undergoes ester hydrolysis to form sacubitrilat, which is the primary metabolite of sacubitril ( $\sim 76.8 \%$ of total exposure following oral dose of sacubitril/valsartan) [22]. The ester hydrolysis of sacubitril is primarily mediated via carboxylesterase 1, but not carboxylesterase 2 [35]. The role of other carboxylesterases remains unknown. Valsar$\tan$ is minimally metabolized with approximately $20 \%$ of the dose recovered as metabolites. Valsartan undergoes 
Table 3 Effect of food on systemic exposure of sacubitrilat and valsartan following single-dose administration of sacubitril/valsartan

\begin{tabular}{|c|c|c|c|}
\hline & \multicolumn{2}{|c|}{ Sacubitril/valsartan $400 \mathrm{mg}$} & \multirow{2}{*}{$\begin{array}{l}\text { Sacubitril/valsartan } 200 \mathrm{mg} \\
\text { Japanese meal }\end{array}$} \\
\hline & Low fat & High fat & \\
\hline \multicolumn{4}{|c|}{ Sacubitrilat } \\
\hline $\mathrm{AUC}_{\mathrm{inf}}$ & $0.84(0.72-0.95)$ & $1.00(0.86-1.15)$ & $0.79(0.68-0.93)$ \\
\hline $\mathrm{AUC}_{\text {last }}$ & $0.84(0.73-0.95)$ & $1.05(0.92-1.19)$ & $0.79(0.67-0.93)$ \\
\hline $\mathrm{C}_{\max }$ & $0.52(0.42-0.64)$ & $0.44(0.35-0.53)$ & $0.28(0.20-0.41)$ \\
\hline \multicolumn{4}{|c|}{ Sacubitrilat } \\
\hline $\mathrm{AUC}_{\mathrm{inf}}$ & $1.0(0.97-1.02)$ & $1.04(1.01-1.06)$ & $0.92(0.90-0.95)$ \\
\hline $\mathrm{AUC}_{\text {last }}$ & $0.91(0.8-1.03)$ & $1.04(0.92-1.18)$ & $0.92(0.90-0.95)$ \\
\hline $\mathrm{C}_{\max }$ & $0.81(0.7-0.92)$ & $0.72(0.63-0.82)$ & $0.73(0.70-0.77)$ \\
\hline \multicolumn{4}{|l|}{ Valsartan } \\
\hline $\mathrm{AUC}_{\mathrm{inf}}$ & $0.66(0.57-0.75)$ & $0.91(0.79-1.04)$ & $0.60(0.45-0.81)$ \\
\hline $\mathrm{AUC}_{\text {last }}$ & $0.67(0.58-0.76)$ & $0.91(0.79-1.04)$ & $0.60(0.45-0.81)$ \\
\hline $\mathrm{C}_{\max }$ & $0.61(0.51-0.71)$ & $0.6(0.51-0.70)$ & $0.49(0.33-0.73)$ \\
\hline
\end{tabular}

CYP2C9-mediated metabolism to form the minor metabolite $(9 \%)$ valeryl 4-hydroxy valsartan $[36,37]$.

\subsection{Elimination}

The apparent clearance (CL/F) of sacubitril and valsartan are 51.1 and $5.4 \mathrm{~L} / \mathrm{h}$ (Table 2), with an estimated half-life of approximately $1.4,11.5$, and $9.9 \mathrm{~h}$, for sacubitril, sacubitrilat, and valsartan, respectively, in healthy subjects [27]. Following oral administration, approximately 52-68\% of sacubitril (primarily as sacubitrilat) and approximately $13 \%$ of valsartan and its metabolites are excreted in urine; $37-48 \%$ of sacubitril (primarily as sacubitrilat), and $86 \%$ of valsartan and its metabolites are excreted in feces. Unchanged sacubitril accounts for $0.8-2.8 \%$ of the dose in urine and $0.3-0.9 \%$ of the dose in feces $[22,27]$.

\section{Pharmacokinetics in Patients with Heart Failure}

In an open-label study in patients with HFrEF, the target patient population, plasma concentrations of all analytes increased rapidly following multiple doses of sacubitril/valsartan (100 mg BID for 7 days and $200 \mathrm{mg}$ BID for 14 days) [38] with a steady-state median $\mathrm{T}_{\max }$ similar to that observed in healthy subjects [25]. The steady-state AUC of sacubitril/valsartan at the 100- and 200-mg BID doses appeared to be dose proportional for both sacubitril and sacubitrilat, and less than dose proportional for valsartan [38].
The pooled analysis of steady-state pharmacokinetics of sacubitril/valsartan $200 \mathrm{mg}$ BID in patients with HFrEF (pooled from two studies) compared with data from healthy subjects (pooled from five studies) are presented in Table 2. The AUCs of sacubitril, sacubitrilat, and valsartan were higher by approximately 1.6-, 2.1-, and 2.3-fold, respectively, in patients with HFrEF compared with healthy subjects, which could be because of reduced clearance potentially owing to altered hepatic and/or renal function in patients with HF [39-41]. Similarly, it was earlier reported that the steady-state AUC and $\mathrm{C}_{\max }$ of valsartan $160 \mathrm{mg}$ BID observed in patients with HFrEF [42] were approximately 1.3-2.0 times higher than those observed in healthy subjects [43]. The CL/F of sacubitril and valsartan was reduced by approximately 2.0- and 3.0-fold, respectively, in patients with HF compared with that observed in healthy subjects. The $\mathrm{CL} / \mathrm{F}$ of sacubitrilat was not determined as it is the active metabolite formed from sacubitril.

Additional information in patients with $\mathrm{HFrEF}$ is available from the PARADIGM-HF trial cohort where 311 patients underwent sparse pharmacokinetic sampling (data on file), the data of which were compared with the pooled data from subjects without HFrEF $(\mathrm{n}=38)$ in three clinical pharmacology studies $[44,45]$. The $\mathrm{CL} / \mathrm{F}$ of valsartan $(5.4$ vs. $3.3 \mathrm{~L} / \mathrm{h})$, sacubitril $(54.8$ vs. $37.1 \mathrm{~L} / \mathrm{h})$, and sacubitrilat $(0.7$ vs. $0.4 \mathrm{~L} / \mathrm{h})$ in patients with $\mathrm{HFrEF}$ was approximately two-times lower than that observed in subjects without HFrEF (pooled data from three clinical pharmacology studies) $[44,45]$. The estimated half-life in patients with HFrEF was comparable but slightly higher to that observed in subjects without HFrEF for valsartan 
$(13.6 \mathrm{~h})$ and sacubitril $(6.0 \mathrm{~h})$; however, $\sim 50 \%$ greater for sacubitrilat $(13.0 \mathrm{~h})$. The predicted accumulation in patients with HFrEF appeared to be $\sim$ twofold higher than that observed in subjects without HFrEF for valsartan (1.9 vs. 1.2) and sacubitrilat (3.3 vs. 1.7); whereas no appreciable accumulation of sacubitril was observed in either population. The mean absorption rate for patients with HFrEF compared with subjects without HFrEF was approximately twofold lower for valsartan $(0.16 \pm 0.07$ vs. $0.29 \pm 0.07$ per hour), whereas no difference was observed for sacubitril $(1.35 \pm 0.09$ vs. $1.34 \pm 0.15$ per hour). Exposure to sacubitril/valsartan observed in the PARADIGM-HF trial using sparse pharmacokinetic sampling is comparable to that observed in the study with intense pharmacokinetic sampling [38].

\section{Drug-Drug Interactions}

Heart failure guidelines recommend the use of angiotensinconverting enzyme inhibitors/angiotensin receptor blockers, $\beta$-blockers, and aldosterone antagonists for the treatment of HFrEF [1, 46]. In addition, several patients are being treated with diuretics, digoxin, warfarin, and other medications (e.g., anti-hypertensive agents and lipid-lowering drugs) related to prevalent co-morbidities. Sacubitril/valsartan was assessed for potential pharmacokinetic or pharmacodynamic drug-drug interactions that could result in differences in the exposure or response to treatment.

Metabolism of sacubitril, sacubitrilat, and valsartan by CYP450 enzymes is minimal and inhibition/induction potential of CYP450 enzymes by sacubitril, sacubitrilat, and valsartan is low. Both sacubitrilat and valsartan are weak inhibitors of CYP2C9. Therefore, pharmacokinetic drug-drug interactions with inhibitors, inducers, or substrates of CYP450 enzymes are unlikely. In-vitro inhibition of organic anion transporter protein (OATP) 1B1 [halfmaximal inhibitory concentration (IC50), $1.9 \mu \mathrm{M}$ ], OATP1B3 (IC50, $3.8 \mu \mathrm{M}$ ) [47], and OAT3 (IC50, $0.8 \mu \mathrm{M}$ ) by sacubitril was observed at clinically relevant concentrations. Sacubitrilat and valsartan were found to be a substrate of OAT3 in vitro; however, a clinically relevant drug-drug interaction at therapeutic doses is unlikely to happen (data on file). Sacubitril is a P-gp substrate. Although no study has been conducted to determine the impact of P-gp inhibition on the bioavailability of sacubitril, the impact is expected to be minimal considering high permeability and bioavailability $(>60 \%)$ of sacubitril.

A total of 13 clinical pharmacology studies were conducted to evaluate the pharmacokinetic and/or pharmacodynamic drug-drug interaction potential with medicines that may be co-administered with sacubitril/valsartan in patients with HFrEF [25, 29, 47-49]. The mechanistic pharmacokinetic drug interaction potential of sacubitril/valsartan was evaluated with CYP3A4, CYP2C9, CYP2C19, CYP2D6, and other CYP enzyme substrates (carvedilol, omeprazole, warfarin, and amlodipine); P-gp (digoxin); OATP1B1/OATP1B3 (atorvastatin and simvastatin); and OAT3 (furosemide). In addition, the pharmacokinetic and pharmacodynamic interaction potential with nitroglycerine and sildenafil was also evaluated because the pharmacodynamic actions are mediated through a common second messenger, cGMP. The pharmacokinetic drug-drug interaction potential was also evaluated with other common co-medications such as antidiabetic agents (metformin), antihypertensive agents (hydrochlorothiazide, HCTZ), and a combination of oral contraceptives (COCs). The effects of co-administration on the pharmacokinetics of either sacubitril/valsartan or the concomitant medication is presented in Fig. 2.

\subsection{Carvedilol}

Carvedilol, a non-selective b-blocker and a substrate for CYP2C9, CYP2D6, and P-gp [50-52], demonstrated efficacy in reducing the risk of death in patients with $\mathrm{HFrEF}$ $[3,53]$ and may thus be co-administered with sacubitril/valsartan. Co-administration of sacubitril/valsartan (400 mg QD) for 5 days showed no impact on steady-state pharmacokinetics of both $\mathrm{R}(+)$ - and $\mathrm{S}(-)$-carvedilol enantiomers in healthy subjects [48]. While steady-state pharmacokinetics of sacubitrilat remained unchanged, the AUC and $\mathrm{C}_{\max }$ of valsartan decreased marginally by 12 and $9 \%$, respectively [48]. This is not considered to be clinically relevant as the observed changes were smaller than the intra-individual variability. These results support the lack of inhibition of aforementioned CYP enzymes by sacubitril/valsartan analytes.

\subsection{Omeprazole}

Omeprazole, a proton pump inhibitor and a substrate of CYP3A4 and CYP2C19, is widely used for the treatment of gastric acid-related disorders in patients with different diseases including cardiovascular disease [54-56]. An increase in gastric $\mathrm{pH}$ following administration of omeprazole can interfere with the absorption of co-medications with $\mathrm{pH}$-dependent solubility [55]. Because the solubility of valsartan and sacubitril (weak acids) is higher at higher $\mathrm{pH}$ conditions, the dissolution rate is also expected to be higher. Therefore, a potential for increased bioavailability of sacubitril/valsartan exists when co-administered with omeprazole. Following administration of omeprazole (40 mg QD) for 5 days in healthy subjects and co-administration of single-dose sacubitril/valsartan $400 \mathrm{mg}$ on day 5 , the $\mathrm{T}_{\max }$ of all three sacubitril/valsartan 
a
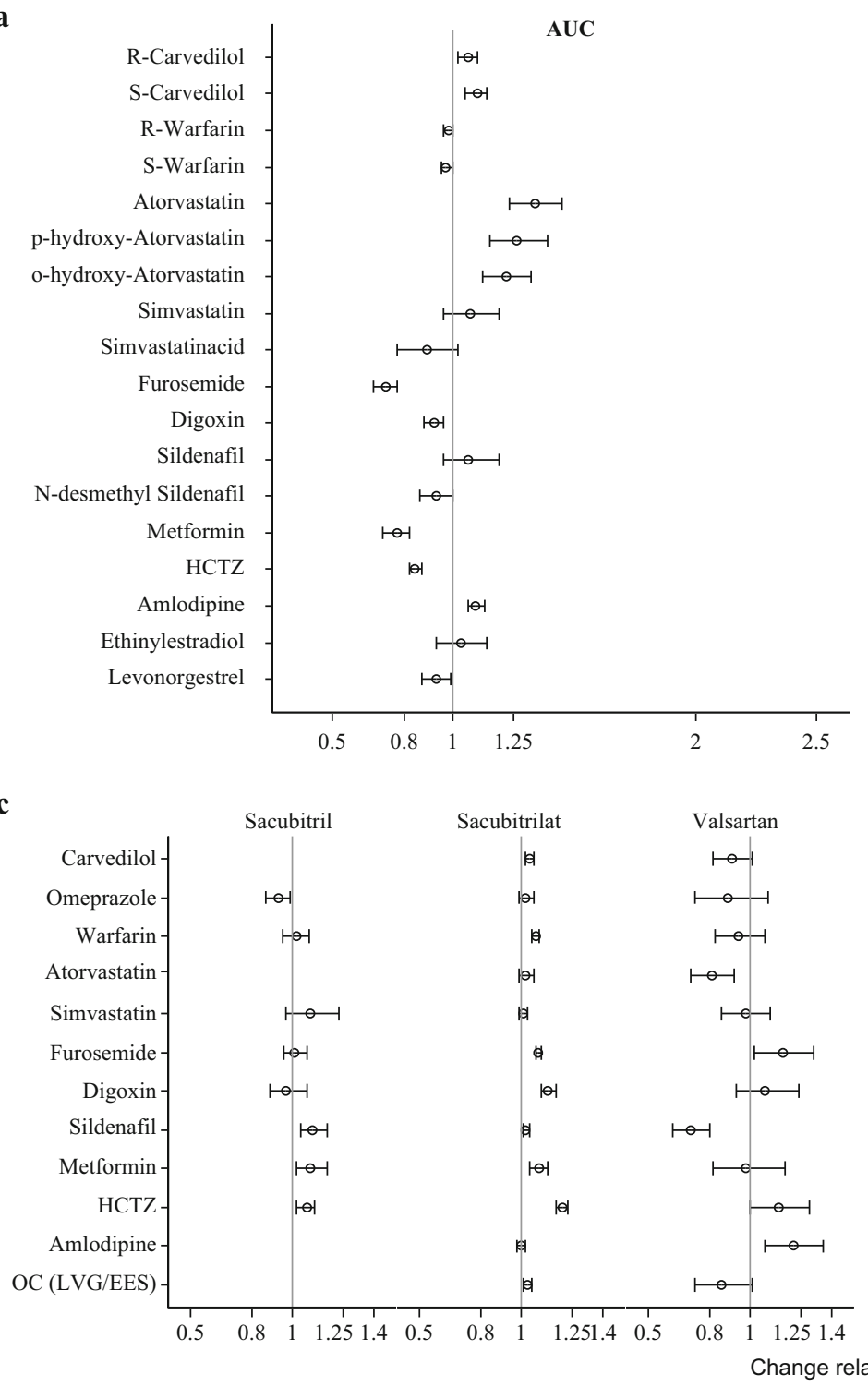

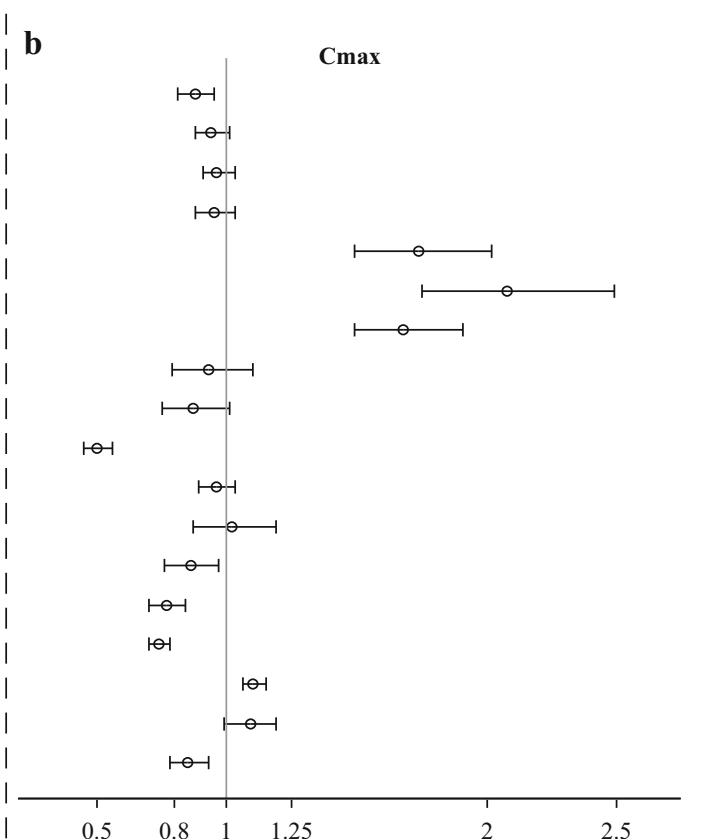

d

\section{Sacubitrilat}

闭
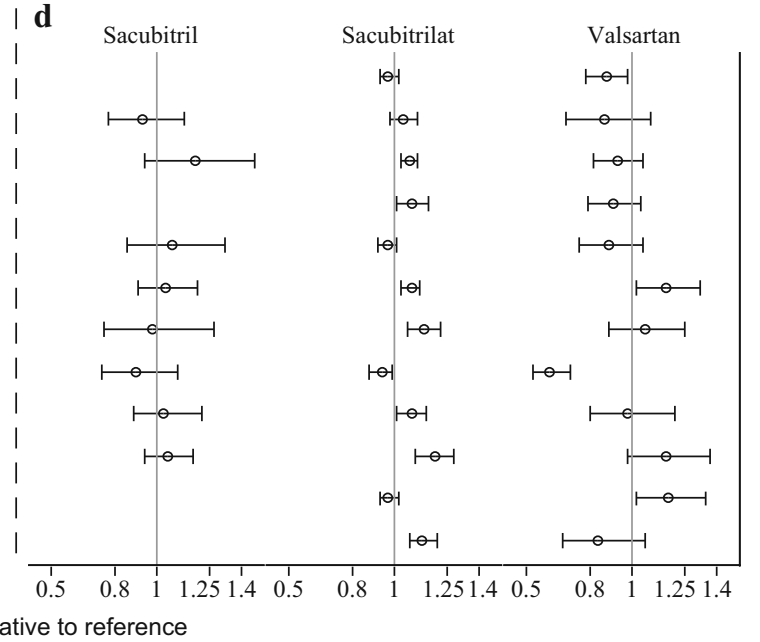

Fig. 2 Drug-drug interactions between sacubitril/valsartan and coadministered medicines. Effect of co-administered medicines on area under the plasma concentration-time curve (AUC) (a) and maximum plasma concentration $\left(\mathrm{C}_{\max }\right)(\mathrm{b})$ of analytes of sacubitril/valsartan;

analytes remained unchanged [49]. The AUC remained unchanged [as $90 \%$ confidence interval (CI) were within 0.8-0.12], while the marginal decrease in $\mathrm{C}_{\max }$ of sacubitril was decreased by $7 \%$ and is considered not to be clinical relevant [49]. This is because the lower bound of $90 \% \mathrm{CI}$ of $\mathrm{C}_{\max }$ of sacubitril (0.77) was only slightly lower than 0.8 , but still within the high inter-subject variability of $\mathrm{C}_{\max }$ $(>70 \%)$ of sacubitril [49]. For sacubitrilat, co-administration did not affect any pharmacokinetic parameter, whereas a marginal decrease in $\mathrm{AUC}_{\mathrm{inf}}$ and $\mathrm{C}_{\max }$ (by 11 and 13\%, respectively) was observed for valsartan [49]. However, it should be noted that valsartan typically shows high and the effect of sacubitril/valsartan on AUC (c) and $\mathrm{C}_{\max }$ (d) of coadministered medicines. EES ethinyl estradiol, HCTZ hydrochlorothiazide, $L V G$ levonorgestrel, $O C$ oral contraceptive

variability $(>40 \%)$ in its pharmacokinetic parameters [57]. Co-administration of sacubitril/valsartan with omeprazole was not associated with clinically relevant pharmacokinetic drug interactions.

\subsection{Warfarin}

Warfarin, a vitamin $\mathrm{K}$ antagonist, is a widely used anticoagulant for the long-term prevention of thrombosis [58]. Minor changes in pharmacokinetic exposure to warfarin may have considerable impact on its safety and efficacy owing to its narrow therapeutic index. Metabolism is 
primarily by CYP2C9 for $\mathrm{S}(-)$-warfarin and by CYP1A2, CYP3A4, and CYP2C19 for $\mathrm{R}(+)$-warfarin $[59,60]$. Therefore, co-administration with CYP inhibitors can increase the concentration of warfarin enantiomers, thereby increasing the anticoagulant effect and risk of bleeding [61]. An in vitro study identified a weak inhibition of CYP2C19 by sacubitril (IC50, $20 \mu \mathrm{M}$ ) and of CYP2C9 by sacubitrilat (IC50, $\sim 40 \mu \mathrm{M}$ ) [22]. However, administration of a single $25-\mathrm{mg}$ dose of warfarin on day 5 of sacubitril/valsartan $200 \mathrm{mg}$ BID in healthy subjects did not impact the pharmacokinetics of $\mathrm{R}(+)$ - and $\mathrm{S}(-)$-warfarin enantiomers as the geometric mean ratio (GMR) and corresponding 90\% CIs were within the 0.8-1.25 range for both $\mathrm{C}_{\max }$ and AUC [25]. Consistent with the lack of a pharmacokinetic interaction, no pharmacodynamic interaction was evidenced by unchanged prothrombin time and International Normalized Ratio values following co-administration of sacubitril/valsartan and warfarin. Moreover, warfarin had no effect on the steady-state pharmacokinetics of sacubitril/valsartan.

\subsection{Statins}

Inhibitors of 3-hydroxy-3-methylglutaryl coenzyme reductase (statins) are the first-line pharmacological treatment for hypercholesterolemia [62, 63]. Statin therapy reduces the risk of acute coronary syndromes, coronary procedures, and other coronary outcomes in both primary and secondary prevention $[62,63]$. In the recently reported PARADIGM-HF trial, about $56 \%$ of patients were receiving statins [64]. Statins are eliminated via CYP-mediated metabolism and/or biliary excretion following hepatic uptake mediated by OATPs, particularly OATP1B1 and OATP1B3 [65, 66]. Organic anion transporter proteins are important molecular targets for transporter-mediated drug-drug interactions, and several such interactions have been reported with statins [67-69]. More importantly, coadministration with CYP and OATP1B1/1B3 inhibitors could increase the exposure to statins, thereby increasing the risk of statin-related adverse events including myopathy and rhabdomyolysis [70].

In-vitro inhibition of OATP1B1 (IC50, $1.9 \mu \mathrm{M})$ and OATP1B3 (IC50, $3.8 \mu \mathrm{M}$ ) by sacubitril indicates a potential for drug-drug interactions following co-administration of sacubitril/valsartan and statins [47]. Two studies determining the pharmacokinetic drug-drug interaction potential of sacubitril/valsartan with statins (atorvastatin $80 \mathrm{mg}$ QD and simvastatin $40 \mathrm{mg}$ QD) were conducted in healthy subjects [29, 47]. Multiple-dose administration of sacubitril/valsartan (200 mg BID) with atorvastatin $80 \mathrm{mg}$ QD increased the steady-state $\mathrm{C}_{\max }$ and AUC of atorvastatin (by 74 and $34 \%$, respectively) and its active metabolites $o$-hydroxyatorvastatin (by 68 and 22\%, respectively) and $p$-hydroxyatorvastatin (by 108 and $26 \%$, respectively) measured on day 5 [29]. Considering the increased $\mathrm{C}_{\max }$, caution is recommended when co-administering statins with sacubitril/valsartan.

In contrast to atorvastatin, sacubitril/valsartan $(200 \mathrm{mg}$ BID at steady state) showed no marked effects on the pharmacokinetics of simvastatin and its active metabolite, simvastatin acid. Because simvastatin acid was shown to be a more sensitive substrate of OATP1B1 than atorvastatin, it is difficult to explain the observed differences in the impact of sacubitril/valsartan on the pharmacokinetics of atorvastatin and simvastatin acid. However, the magnitude of increase in the AUC of atorvastatin with sacubitrilat/valsartan co-administration was not high, suggesting a limited impact of OATP1B1/1B3 inhibition by sacubitril. This can be attributed to transient inhibition caused by rapid absorption $\left(\mathrm{T}_{\max } \sim 0.5 \mathrm{~h}\right)$ and elimination (half-life $\sim 1.5 \mathrm{~h}$ ) of sacubitril, leading to a very low plasma concentrations at $4 \mathrm{~h}$ post-dose of sacubitril/valsartan. Therefore, the effect is limited to $\mathrm{C}_{\max }$ of atorvastatin and its metabolites and not to the total exposure. Perhaps this also explains the absence of any marked interaction when sacubitril/valsartan was co-administrated with simvastatin, because both simvastatin and simvastatin acid are absorbed slowly, reaching $\mathrm{C}_{\max }(4 \mathrm{~h})$ after $\mathrm{T}_{\max }$ of sacubitril.

\subsection{Furosemide}

Furosemide is a loop diuretic and a known substrate for OAT3, which is involved in furosemide renal excretion [71]. Co-administration with any drug that could potentially inhibit the OAT3 transporter can affect the pharmacokinetics and pharmacodynamics of furosemide. In-vitro studies have shown that sacubitrilat and valsartan can potentially inhibit OAT3 (IC50, 15.2 and $1.1 \mu \mathrm{M}$, respectively; data on file for sacubitrilat) [72]. Co-administration of sacubitril/valsartan (at steady state following 5 days administration of $200 \mathrm{mg}$ BID) and furosemide (40 mg) single dose in healthy subjects showed no impact on the steady-state AUCs of sacubitril and sacubitrilat. Valsartan AUC was increased by $15 \%$, which is not clinically significant considering its high variability of exposure (data on file). However, co-administration of both drugs decreased the $\mathrm{C}_{\max }$ and AUC of furosemide significantly by 50 and $28 \%$, respectively, while urinary excretion of furosemide was reduced by $26 \%$. The potential reduction in the absorption and decrease in the $\mathrm{C}_{\max }$ of furosemide following sacubitril/valsartan co-administration could be the reason for the observed decrease in AUC. Furosemide absorption and bioavailability are highly variable owing to high inter-subject variability and poor solubility, and further depend on gastric emptying and gastric $\mathrm{pH}$ [73]. Furthermore, in previous pharmacokinetic studies, co- 
administration of valsartan and furosemide resulted in a $26 \%$ reduction in furosemide AUC [74].

Co-administration of sacubitril/valsartan and furosemide compared with the administration of furosemide alone led to a reduction in urine volume within 0-4 h (by $119 \mathrm{~mL}$ ) and 4-8 h (by $124 \mathrm{~mL}$ ), while there was no impact on the overall urine volume over $24 \mathrm{~h}$. Furthermore, 24-h natriuresis was decreased by $\sim 30 \mathrm{mmol}$; this effect was mostly driven by a reduction in natriuresis within the initial $4 \mathrm{~h}$ of dosing. However, there was no impact on mean urinary excretion of potassium.

In a post hoc analysis of the pivotal phase III PARADIGM-HF trial, patients receiving furosemide, sacubitril/valsartan $(\mathrm{n}=685)$ compared with enalapril $(\mathrm{n}=745)$ was associated with a smaller increase in the average daily dose (16.5 vs. $26.2 \mathrm{mg}$ ) but with no increase in the median daily dose ( 0 vs. $20 \mathrm{mg}$ ) of furosemide.

In summary, while the exposure of furosemide was decreased with sacubitril/valsartan co-administration, no impact was observed on the pharmacodynamics (24-h urine volume) and the median daily dose of furosemide remained unchanged in the PARADIGM-HF trial.

\subsection{Digoxin}

Digoxin, a cardiac glycoside, is widely prescribed for the treatment of HFrEF [75, 76]. Digoxin undergoes P-gpmediated transport in the intestine and kidney [77-79]. Coadministration with a drug that can inhibit/share P-gp transport or elimination can affect the disposition of digoxin, which is relevant owing to its narrow therapeutic index. Sacubitril is a substrate of P-gp.

However, co-administration of sacubitril/valsartan $200 \mathrm{mg}$ BID for 4 days following administration of digoxin for 10 days in healthy subjects did not alter the steady-state pharmacokinetics of digoxin as the GMR and corresponding $90 \%$ CIs for both $\mathrm{C}_{\max }$ and $\mathrm{AUC}$ of the active analytes and digoxin were within $80-125 \%$ confidence limits, demonstrating no interaction between sacubitril/valsartan and digoxin [25].

\subsection{Nitroglycerin}

Nitroglycerin releases nitric oxide that effectively lowers blood pressure (BP) and is indicated for symptomatic treatment of coronary artery disease, a common co-morbidity in patients with HFrEF [80]. Natriuretic peptides, elevated by inhibition of their degradation by sacubitrilat, and nitroglycerin have a common second messenger, cGMP. Therefore, the pharmacodynamic interaction potential between sacubitril/valsartan (200 mg BID) and intravenous nitroglycerin was evaluated in healthy subjects (data on file).
Co-administration with nitroglycerin did not impact the pharmacokinetics of sacubitril/valsartan. The GMR $(90 \% \mathrm{CI})$ of $\mathrm{AUC}_{\mathrm{tau}}$ and $\mathrm{C}_{\max }$ for sacubitrilat were 1.02 (1.0-1.04) and 0.99 (0.94-1.04), respectively and for valsartan were $1.13(1.04-1.23)$ and 1.06 (0.94-1.19), respectively when sacubitril/valsartan administered alone was compared with nitroglycerin co-administration. The pharmacokinetics of nitroglycerin has not been studied considering the technical difficulties of quickly forming nitrate bioanalytics with a short half-life. Therefore, the primary objective was to evaluate a pharmacodynamics interaction.

The dose- and time-dependent reductions in systolic and diastolic BP were not significantly different between administration of nitroglycerin alone and co-administration of nitroglycerin and sacubitril/valsartan. In addition, the maximal BP decrease was similar with nitroglycerin alone $(-22.5 /-14.4 \mathrm{mmHg})$ and with the co-administration of nitroglycerin and sacubitril/valsartan (-23.9/$13.3 \mathrm{mmHg}$ ). Moreover, the increase in cGMP was not significantly different following co-administration of both drugs compared with sacubitril/valsartan alone, indicating a lack of a pharmacodynamic interaction between sacubitril/valsartan and nitroglycerin. Therefore, the label-recommended dose escalation and clinical monitoring of nitroglycerin is adequate for patients treated with sacubitril/valsartan.

\subsection{Sildenafil}

Sildenafil, a phosphodiesterase-5 inhibitor, inhibits the degradation of cGMP and is indicated for erectile dysfunction. Considering the high prevalence of erectile dysfunction in patients with $\mathrm{HF}$ there is a potential of coadministration with sacubitril/valsartan. Owing to their common second messenger cGMP, the potential for pharmacokinetic and pharmacodynamic interactions was evaluated in patients with mild-to-moderate hypertension (data on file). Co-administration of sildenafil $(50 \mathrm{mg})$ following administration of sacubitril/valsartan (400 mg QD for 5 days) did not impact the $\mathrm{C}_{\max }$ and AUC of sildenafil and the AUC of its metabolite, $N$-desmethyl sildenafil. A minor decrease in the $\mathrm{C}_{\max }$ of $N$-desmethyl sildenafil (14\%) was not considered clinically relevant because it was within the observed pharmacokinetic variability (46\%) [81]. Sildenafil did not affect the pharmacokinetics of sacubitrilat; however, it decreased the $\mathrm{C}_{\max }$ and $\mathrm{AUC}$ of valsartan by approximately 39 and $29 \%$, respectively. Co-administration of sacubitril/valsartan and sildenafil resulted in an additive reduction in ambulatory BP (particularly, daytime and 24-h BP), which may not be desirable in patients with HF. Therefore, sildenafil should be used with caution in patients treated with sacubitril/valsartan. 


\subsection{Metformin}

Metformin is widely prescribed for type 2 diabetes mellitus, a common co-morbidity in HFrEF. Following co-administration of sacubitril/valsartan (400 mg QD) and metformin (1000 mg QD) for 4 days, the steady-state pharmacokinetics of all analytes of sacubitril/valsartan remained unaltered, while a decrease in $\mathrm{C}_{\max }$ and AUC of metformin by $23 \%$ was observed [49]. The clinical relevance of these findings is unknown. However, considering the high inter-individual variability of metformin plasma concentrations and up-titration of metformin dose up to $2250 \mathrm{mg} /$ day based on the glycemic response and tolerability, this decrease is unlikely to be clinically relevant.

\subsection{Hydrochlorothiazide (HCTZ)}

Diuretics including HCTZ are the first-line treatment for hypertension [82]. A drug-drug interaction study between sacubitril/valsartan and HCTZ was conducted to evaluate the potential for interference with renal clearance as it is the primary elimination pathway for sacubitrilat [22] and HCTZ [83, 84]. Following co-administration of sacubitril/valsartan $400 \mathrm{mg}$ QD and HCTZ $25 \mathrm{mg}$ QD for 4 days in healthy subjects, steady-state $\mathrm{C}_{\max }$ of HCTZ was decreased by $26 \%$, whereas an increase in the $\mathrm{C}_{\max }$ of sacubitrilat and valsartan by 19 and $16 \%$, respectively, was observed. Although the GMR is 0.85 , the $90 \%$ CIs of GMRs for AUCs of HCTZ and sacubitrilat were within the $0.80-1.25$ interval, whereas the AUC of valsartan was increased by $14 \%$ [48]. The observed changes in the AUC of HCTZ and the analytes of sacubitril/valsartan were smaller than the coefficients of variation of estimated pharmacokinetic parameters [48]. Therefore, these observations demonstrated no clinically relevant interactions when sacubitrilat/valsartan and HCTZ were coadministered.

\subsection{Amlodipine}

Amlodipine, a dihydropyridine calcium channel blocker, is a widely prescribed anti-hypertensive agent [85-88]. Metabolic clearance of amlodipine is primarily mediated by CYP3A4 [89] and is therefore not anticipated to be affected by co-administration of sacubitril/valsartan. Further, co-administration of sacubitril/valsartan (400 mg QD) and amlodipine (10 mg QD) for 5 days in healthy subjects did not impact the steady-state pharmacokinetics of amlodipine or sacubitrilat, while the steady-state $\mathrm{C}_{\max }$ and AUC of valsartan increased marginally by 17 and $21 \%$, respectively [48]. These minor changes are not considered to be clinically relevant.

\subsection{Oral Contraceptives}

Levonorgestrel $150 \mathrm{mg} /$ ethinyl estradiol $30 \mathrm{mg}$ is a widely used combined oral contraceptive (COC) and is primarily metabolized by CYP3A4 [90, 91]. Sacubitril/valsartan analytes did not inhibit/induce CYP3A4 in vitro $[22,36]$. As expected, co-administration of $\mathrm{COC}$ following administration of sacubitril/valsartan $400 \mathrm{mg}$ QD for 7 days in healthy subjects did not impact the AUC and $C_{\max }$ of ethinyl estradiol and AUC of levonorgestrel, while the $\mathrm{C}_{\max }$ of levonorgestrel was decreased by $15 \%$ [49]. Because the exposure of levonorgestrel was unchanged and the effect on $\mathrm{C}_{\max }$ was small and within the pharmacokinetic variability, the observed changes in $\mathrm{C}_{\max }$ are not considered to be clinically relevant and to impact the efficacy of the COC. The pharmacokinetics of sacubitrilat was unchanged, while the $\mathrm{C}_{\max }$ and AUC of valsartan were decreased by 16 and $14 \%$, respectively with COC co-administration. These findings suggest no clinically relevant drug-drug interactions between levonorgestrel/ethinyl estradiol and sacubitril/valsartan.

\section{Effect of Demographics on Sacubitril/Valsartan Pharmacokinetics}

\subsection{Body Weight}

A pooled analysis from four studies [48, 49] showed no impact of body weight or body mass index on the pharmacokinetics of sacubitrilat and valsartan. Furthermore, a regression analysis showed no statistically significant impact of body weight on steady-state trough plasma concentrations of sacubitrilat and valsartan using pooled data from two studies $(\mathrm{n}=250)$ on sacubitrilat/valsartan $(100,200$, and $400 \mathrm{mg})$ [92, 93] conducted in Japanese patients with hypertension (data on file).

\subsection{Age and Sex}

The effect of age on pharmacokinetics of all the analytes following single-dose administration of sacubitril/valsartan $400 \mathrm{mg}$ was assessed in both young and elderly healthy subjects [94]. In elderly subjects (aged $\geq 65$ and $\geq 75$ years), the AUC of sacubitrilat was $42 \%$ higher compared with young subjects (aged 18-45 years), whereas the $\mathrm{C}_{\max }$ was similar (Fig. 3). The AUC and $\mathrm{C}_{\max }$ of valsartan were higher by 30 and $24 \%$, respectively, in the elderly subjects compared with young subjects. Decreased clearance, potentially owing to a decrease in renal and hepatic function with age, could be the reason for the observed differences in the pharmacokinetics of sacubitril/valsartan analytes in elderly subjects. However, these 


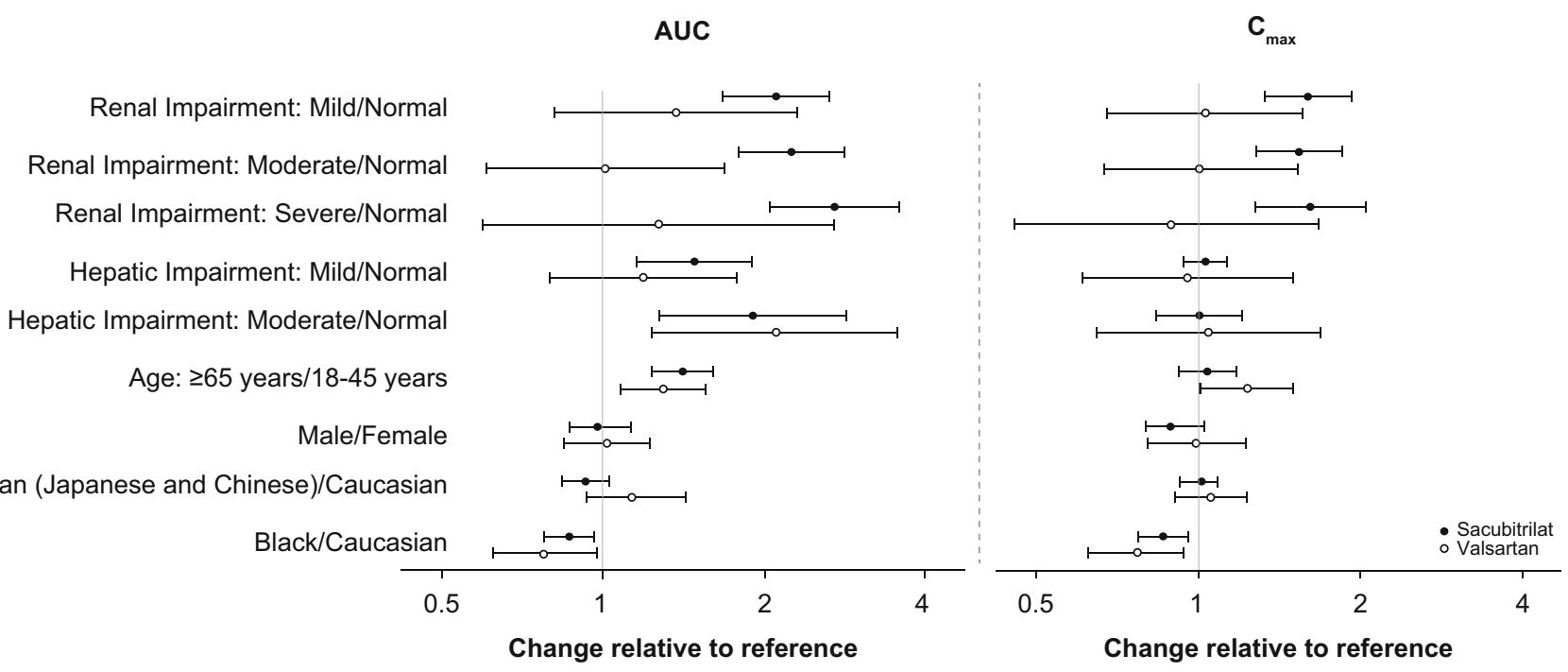

Fig. 3 Effect of demographics and co-morbid disease conditions on the pharmacokinetics of sacubitril/valsartan. AUC area under the plasma concentration-time curve, $C_{\max }$ maximum plasma concentration

are not considered to be clinically relevant as sacubitril/valsartan is shown to be generally safe and well tolerated in patients aged $>65$ years in the PARADIGM-HF trial [95]. The pharmacokinetics of sacubitrilat and valsartan were similar between male and female subjects (Fig. 3). Hence, no dose adjustment of sacubitril/valsartan is required, regardless of age or sex.

\subsection{Race/Ethnicity}

A pooled analysis from five studies (Table 2) showed comparable AUC and $\mathrm{C}_{\max }$ of sacubitril, sacubitrilat, and valsartan across different races and ethnicities in healthy subjects following the administration of a single dose of $200 \mathrm{mg}$ of sacubitril/valsartan (Fig. 3). The formation of sacubitrilat from sacubitril is mediated by carboxylesterase 1 , an enzyme which is shown to have distinct ethnic differences based on genetic polymorphisms and haplotype frequencies [96]. However, these differences did not impact its activity, measured as the ratio of oseltamivir carboxylate/oseltamivir, a carboxylesterase 1-mediated conversion [97]. Our pooled analysis, which revealed no clinically relevant impact of race and ethnicity on pharmacokinetics of sacubitril and sacubitrilat, also suggested that carboxylesterase 1 polymorphisms are unlikely to affect the conversion of sacubitril to sacubitrilat.

\section{Pharmacokinetics of Sacubitril/Valsartan in Special Populations}

The pharmacokinetics of sacubitril/valsartan was evaluated in patients with renal and hepatic impairment (Fig. 3). The pharmacokinetics of sacubitril/valsartan in the elderly is described in the previous section. The assessment of safety and efficacy of sacubitril/valsartan in children is currently ongoing; no results are available at the time of compiling this review.

\subsection{Patients with Renal Impairment}

Renal impairment is a common co-morbidity in patients with $\mathrm{HFrEF}$, with nearly $90 \%$ of patients showing some degree of renal dysfunction [41]. Renal excretion is the primary route of elimination of sacubitril $(52-68 \%$ of the dose), primarily as sacubitrilat, while only $\sim 13 \%$ of valsartan and its metabolites are excreted in urine [22]. Renal impairment did not impact the exposure to sacubitril and valsartan; both $\mathrm{C}_{\max }$ and $\mathrm{AUC}$ of each analyte remained

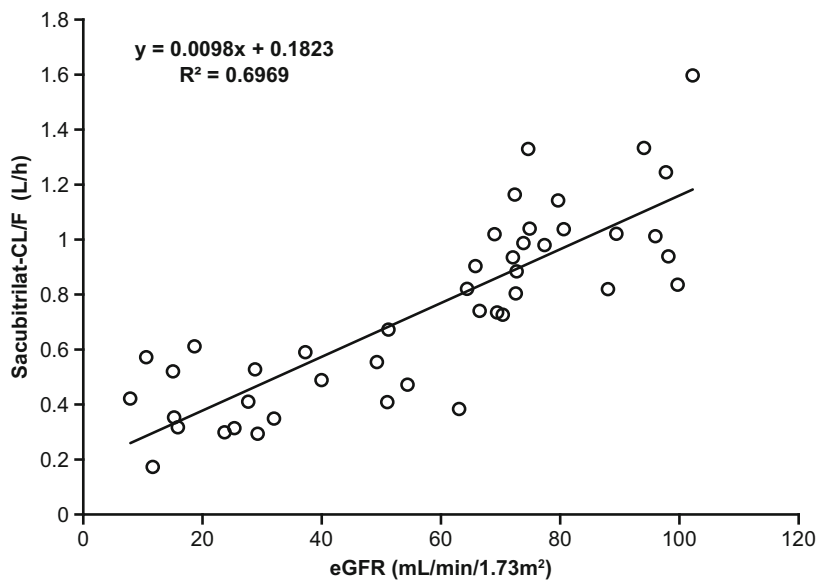

Fig. 4 Correlation between estimated glomerular filtration rate (eGFR) and systemic clearance of sacubitrilat, an active analyte of sacubitril/valsartan. $C L / F$ apparent clearance 
unchanged in patients with renal impairment compared with healthy subjects. Compared with healthy subjects, the AUC to sacubitrilat was not impacted by mild $(60-89 \mathrm{~mL} /$ $\min / 1.73 \mathrm{~m}^{2}$ ) renal impairment (characterized using the Modification of Diet in Renal Disease formula [98]), whereas it was 2.3-, 2.9-, and 3.3-fold higher in patients with moderate- $\left(30-59 \mathrm{~mL} / \mathrm{min} / 1.73 \mathrm{~m}^{2}\right)$ and severe (15-29 $\mathrm{mL} / \mathrm{min} / 1.73 \mathrm{~m}^{2}$ ) renal impairment, and end-stage renal disease $\left(15 \mathrm{~mL} / \mathrm{min} / 1.73 \mathrm{~m}^{2}\right)$ without dialysis, respectively (Fig. 3) [44]. No studies have been performed in patients undergoing dialysis. However, sacubitrilat and valsartan are highly bound to plasma protein, and are therefore unlikely to be removed by dialysis. A moderateto-high correlation between $\mathrm{CL} / \mathrm{F}$ of sacubitrilat and estimated glomerular filtration rate was observed $\left(\mathrm{R}^{2} 0.6969\right)$; the linear relationship between sacubitrilat clearance and estimated glomerular filtration rate could be described by $\mathrm{CL} / \mathrm{F}=0.0098 \times \mathrm{eGFR}+0.182$ (Fig. 4). In patients with $\mathrm{HFrEF}$ and co-morbid renal impairment, a subgroup analysis of the PARADIGM-HF trial indicated an $\sim 1$.8-fold increase in the AUC of sacubitrilat in patients with moderate renal impairment, and an $\sim 2$.0-fold increase in those with severe renal impairment, compared with patients with HFrEF and normal renal function. However, no impact on AUC of sacubitril and valsartan was observed (data on file). The starting dose should be adjusted depending on the degree of renal function of patients.

\subsection{Patients with Hepatic Impairment}

Hepatic clearance is the primary route of elimination of valsartan ( $\sim 83 \%$ of the dose) $[37,99]$ and contributes to the clearance of sacubitril (37-48\% of the dose; primarily as sacubitrilat). Compared with healthy subjects, in patients with mild and moderate hepatic impairment, AUCs increased by 1.5- and 3.4-fold for sacubitril, by 1.5- and 1.9-fold for sacubitrilat, and by 1.2- and 2.1-fold for valsartan, respectively [45]. Despite the increase in the AUC, no impact was observed on the $\mathrm{C}_{\max }$ of sacubitrilat and valsartan (Fig. 3), while the $\mathrm{C}_{\max }$ of sacubitril increased by 1.6- and 3.1-fold in patients with mild and moderate hepatic impairment, respectively.

The increase in AUC of sacubitrilat could be attributed to concomitant renal dysfunction observed in a few subjects with hepatic impairment. This was evidenced by the negative correlation of sacubitril AUC and creatinine clearance [45] and is consistent with similar observation in patients with renal impairment [44]. In contrast, the increase in the AUC and $\mathrm{C}_{\max }$ of sacubitril is not considered to be clinically relevant because sacubitril is an inactive prodrug. The increase in AUC of valsartan was consistent with its primary route of elimination. The starting dose may need to be adjusted depending on the hepatic function of the patient.

\section{Conclusions}

Sacubitril/valsartan is a first-in-class angiotensin receptorneprilysin inhibitor recently approved to reduce the risk of cardiovascular death and HF hospitalization in patients with HFrEF (New York Heart Association II-IV) in several countries worldwide, including USA and Europe. Sacubitril/valsartan is a sodium salt complex of sacubitril (a prodrug) and valsartan (a well-established angiotensin receptor blocker). Sacubitril undergoes carboxylesterase 1-mediated metabolism to form sacubitrilat, an active neprilysin inhibitor. Pharmacokinetics following single and multiple ascending doses of sacubitril/valsartan revealed rapid absorption of sacubitril and valsartan following oral administration and conversion of sacubitril to sacubitrilat. An increase in AUC was dose proportional for sacubitril and 1.9- and 1.7-fold for sacubitrilat and valsartan, respectively, with a twofold increase in the dose. The bioavailability of valsartan is $60 \%$ higher in sacubitril/valsartan than in other marketed tablet formulations. Therefore, a 200-mg dose of sacubitril/valsartan containing $103 \mathrm{mg}$ of valsartan provides systemic exposure similar to that following administration of $160 \mathrm{mg}$ of valsartan in alternate marketed formulations. Sacubitril/valsartan analytes reach steady-state plasma concentrations within 3 days of multiple QD or BID administration. No significant accumulation of either sacubitril or valsartan was observed at the steady state. Accumulation of sacubitrilat was minimal (1.2-fold) with QD administration and significant (1.6-fold) with BID dosing. Food does not have an impact on the pharmacokinetics of sacubitril/valsartan; this was consistent irrespective of dose and formulations. All analytes of sacubitril/valsartan are highly protein bound. The majority of sacubitril (primarily as sacubitrilat) is excreted in urine and a majority of valsartan is excreted in feces.

No clinically relevant drug-drug interactions were observed when sacubitril/valsartan was co-administered with digoxin, warfarin, HCTZ, amlodipine, omeprazole, metformin, carvedilol, or a COC. No pharmacokinetic interaction was observed when sacubitril/valsartan was coadministered with sildenafil; however, caution should be exercised as an additional decrease in BP was observed following co-administration of both drugs. Co-administration of sacubitril/valsartan did not significantly alter the BP-lowering effects of intravenous nitroglycerin. Caution should be exercised when administering sacubitril/valsartan with statins, considering the $\sim$ twofold increase in the $\mathrm{C}_{\max }$ of atorvastatin (with no impact on AUC). However, no significant impact on pharmacokinetics was observed 
for simvastatin acid, a sensitive OATP1B1 substrate. While there was a decrease in the exposure of furosemide in the presence of sacubitril/valsartan, no changes in the 24-h urine volume were observed and median daily dose of furosemide was unchanged in the PARADIGM-HF trial. The exposure of metformin was decreased by $23 \%$ in the presence of sacubitril/valsartan, however, this is not considered to be clinically significant.

No clinically relevant differences were observed in the pharmacokinetics of sacubitril/valsartan between elderly and young subjects. The pharmacokinetics of sacubitrilat and valsartan were similar among male and female subjects, and across race and ethnicities. In patients with HFrEF, the AUCs of sacubitril, sacubitrilat, and valsartan were higher by 1.6-, 2.1-, and 2.3-fold, respectively, and the peak plasma concentrations of all sacubitril/valsartan analytes were higher by $\sim 1$.5-fold. Because the safety and efficacy of sacubitril/valsartan were established in patients with HFrEF in the PARADIGM-HF trial, no dose adjustment is necessary. In patients with renal impairment, AUC of sacubitrilat increased with increasing severity of renal impairment with no impact in patients with mild renal impairment and a 2.3-, 2.9-, and 3.3-fold higher in patients with moderate and severe renal impairment, and end-stage renal disease without dialysis, respectively, compared with healthy subjects. In patients with hepatic impairment, increases in the AUC and $\mathrm{C}_{\max }$ of sacubitril were not considered clinically relevant because it is an inactive prodrug, while the observed increase in the AUC of valsartan was consistent with its route of elimination. The starting dose may need to be adjusted in patients depending on the renal and hepatic function.

Acknowledgements The authors acknowledge Iain O'Neill (contracted to Global Medical and Clinical Services, Novartis Ireland Ltd.) for providing editorial support.

Author Contributions All authors were involved in the preparation of the manuscript, provided input, and reviewed the final draft for the publication.

\section{Compliance with Ethical Standards}

Conflict of interest All authors are employees of Novartis except Surya Ayalasomayajula, who was an employee of Novartis during the development of the manuscript and is currently affiliated with Allergan, plc, NJ, USA.

Funding All clinical pharmacokinetic studies are sponsored by Novartis Pharmaceuticals Co.

\section{References}

1. Ponikowski P, Voors AA, Anker SD, et al. 2016 ESC guidelines for the diagnosis and treatment of acute and chronic heart failure: the Task Force for the diagnosis and treatment of acute and chronic heart failure of the European Society of Cardiology
(ESC). Developed with the special contribution of the Heart Failure Association (HFA) of the ESC. Eur J Heart Fail. 2016;18(8):891-975.

2. Yancy CW, Jessup M, Bozkurt B, et al. 2013 ACCF/AHA guideline for the management of heart failure: executive summary: a report of the American College of Cardiology Foundation/American Heart Association Task Force on practice guidelines. Circulation. 2013;128(16):1810-52.

3. Packer M, Coats AJ, Fowler MB, et al. Effect of carvedilol on survival in severe chronic heart failure. $\mathrm{N}$ Engl $\mathrm{J}$ Med. 2001;344(22):1651-8.

4. MERIT-HF Study Group. Effect of metoprolol CR/XL in chronic heart failure: metoprolol CR/XL Randomised Intervention Trial in Congestive Heart Failure (MERIT-HF). Lancet. 1999;353(9169):2001-7.

5. CIBIS-II Investigators and Committees. The Cardiac Insufficiency Bisoprolol Study II (CIBIS-II): a randomised trial. Lancet. 1999;353(9146):9-13.

6. Pitt B, Zannad F, Remme WJ, et al. The effect of spironolactone on morbidity and mortality in patients with severe heart failure: randomized aldactone evaluation study investigators. N Engl J Med. 1999;341(10):709-17.

7. Zannad F, McMurray JJ, Krum H, et al. Eplerenone in patients with systolic heart failure and mild symptoms. N Engl J Med. 2011;364(1):11-21.

8. Braunwald E. ACE inhibitors: a cornerstone of the treatment of heart failure. N Engl J Med. 1991;325(5):351-3.

9. McMurray JJ. CONSENSUS to EMPHASIS: the overwhelming evidence which makes blockade of the renin-angiotensin-aldosterone system the cornerstone of therapy for systolic heart failure. Eur J Heart Fail. 2011;13(9):929-36.

10. Ponikowski P, Anker SD, AlHabib KF, et al. Heart failure: preventing disease and death worldwide. ESC Heart Fail. 2014;1(1):4-25.

11. Volpe M. Natriuretic peptides and cardio-renal disease. Int $\mathbf{J}$ Cardiol. 2014;176(3):630-9.

12. Daniels LB, Maisel AS. Natriuretic peptides. J Am Coll Cardiol. 2007;50(25):2357-68.

13. Hawkridge AM, Heublein DM, Bergen HR 3rd, et al. Quantitative mass spectral evidence for the absence of circulating brain natriuretic peptide (BNP-32) in severe human heart failure. Proc Natl Acad Sci USA. 2005;102(48):17442-7.

14. Niederkofler EE, Kiernan UA, O'Rear J, et al. Detection of endogenous B-type natriuretic peptide at very low concentrations in patients with heart failure. Circ Heart Fail. 2008;1(4):258-64.

15. Mangiafico S, Costello-Boerrigter LC, Andersen IA, et al. Neutral endopeptidase inhibition and the natriuretic peptide system: an evolving strategy in cardiovascular therapeutics. Eur Heart J. 2013;34(12):886-93.

16. Langenickel TH, Dole WP. Angiotensin receptor-neprilysin inhibition with LCZ696: a novel approach for the treatment of heart failure. Drug Discov Today. 2012;9(4):e131-9.

17. McMurray JJV, Packer M, Desai AS, et al. Angiotensin-neprilysin inhibition versus enalapril in heart failure. N Engl J Med. 2014;371(11):993-1004.

18. Packer M, McMurray JJ, Desai AS, et al. Angiotensin receptor neprilysin inhibition compared with enalapril on the risk of clinical progression in surviving patients with heart failure. Circulation. 2015;131(1):54-61.

19. Yancy CW, Jessup M, Bozkurt B, et al. 2016 ACC/AHA/HFSA focused update on new pharmacological therapy for heart failure: an update of the 2013 ACCF/AHA guideline for the management of heart failure: a report of the American College of Cardiology/American Heart Association Task Force on clinical practice guidelines and the Heart Failure Society of America. J Am Coll Cardiol. 2016;68(13):1476-88. 
20. Vazir A, Solomon SD. Management strategies for heart failure with preserved ejection fraction. Heart Fail Clin. 2014;10(4):591-8.

21. Gu J, Noe A, Chandra P, et al. Pharmacokinetics and pharmacodynamics of LCZ696, a novel dual-acting angiotensin receptor-neprilysin inhibitor (ARNi). J Clin Pharmacol. 2010;50(4):401-14.

22. Flarakos J, Du Y, Bedman T, et al. Disposition and metabolism of [C] sacubitril/valsartan (formerly LCZ696) an angiotensin receptor neprilysin inhibitor, in healthy subjects. Xenobiotica. 2016;46(11):986-1000.

23. Feng L, Karpinski PH, Sutton P, et al. LCZ696: a dual-acting sodium supramolecular complex. Tetrahedron Lett. 2012;53(3):275-6.

24. Ayalasomayajula S, Langenickel T, Chandra P, et al. Effect of food on the oral bioavailability of the angiotensin receptor neprilysin inhibitor sacubitril/valsartan (LCZ696) in healthy subjects. Int J Clin Pharmacol Ther. 2016;54(12):1012-8.

25. Ayalasomayajula S, Jordaan P, Pal P, et al. Assessment of drug interaction potential between LCZ696, an angiotensin receptor neprilysin inhibitor, and digoxin or warfarin. Clin Pharmacol Biopharm. 2015;4:147.

26. Nadeem S, Asif H, Lakshita C, et al. Pharmacological and pharmaceutical profile of valsartan: a review. J Appl Pharm Sci. 2011;01(04):12-9.

27. Novartis. EntrestoTM (sacubitril and valsartan): US prescribing information. 2015. http://www.pharma.us.novartis.com. Accessed 21 Nov 2015.

28. Flesch G, Muller P, Lloyd P. Absolute bioavailability and pharmacokinetics of valsartan, an angiotensin II receptor antagonist, in man. Eur J Clin Pharmacol. 1997;52(2):115-20.

29. Ayalasomayajula S, Pan W, Han Y, et al. Assessment of drug-drug interaction potential between atorvastatin and LCZ696, a novel angiotensin receptor neprilysin inhibitor, in healthy Chinese male subjects. Eur J Drug Metab Pharmacokinet. 2017;42(2):309-18.

30. Akahori M, Ayalasomayajula S, Langenickel T, et al. Pharmacokinetics after single ascending dose, food effect, and safety of sacubitril/valsartan (LCZ696), an angiotensin receptor and neprilysin inhibitor, in healthy Japanese subjects. Eur J Drug Metab Pharmacokinet. 2016 (Epub ahead of print).

31. US Food and Drug Administration. Diovan: prescribing information. 2014. https://www.pharma.us.novartis.com/sites/. http:// www.pharma.us.novartis.com/files/diovan.pdf. Accessed 13 Apr 2017.

32. Sunkara G, Jiang X, Reynolds C, et al. Effect of food on the oral bioavailability of amlodipine/valsartan and amlodipine/valsartan/hydrochlorothiazide fixed dose combination tablets in healthy subjects. Clin Pharmacol Drug Dev. 2014;3(6):487-92.

33. Colussi DM, Parisot C, Rossolino ML, et al. Protein binding in plasma of valsartan, a new angiotensin II receptor antagonist. J Clin Pharmacol. 1997;37(3):214-21.

34. Langenickel TH, Tsubouchi C, Ayalasomayajula S, et al. The effect of LCZ696 (sacubitril/valsartan) on amyloid-beta concentrations in cerebrospinal fluid in healthy subjects. Br J Clin Pharmacol. 2016;81(5):878-90.

35. Shi J, Wang X, Nguyen J, et al. Sacubitril is selectively activated by carboxylesterase 1 (CES1) in the liver and the activation is affected by CES1 genetic variation. Drug Metab Dispos. 2016;44(4):554-9.

36. Nakashima A, Kawashita H, Masuda N, et al. Identification of cytochrome $\mathrm{P} 450$ forms involved in the 4-hydroxylation of valsartan, a potent and specific angiotensin II receptor antagonist, in human liver microsomes. Xenobiotica. 2005;35(6):589-602.

37. Waldmeier F, Flesch G, Muller P, et al. Pharmacokinetics, disposition and biotransformation of [14C]-radiolabelled valsartan in healthy male volunteers after a single oral dose. Xenobiotica. 1997;27(1):59-71.
38. Kobalava Z, Kotovskaya Y, Averkov O, et al. Pharmacodynamic and pharmacokinetic profiles of sacubitril/valsartan (LCZ696) in patients with heart failure and reduced ejection fraction. Cardiovasc Ther. 2016;34(4):191-8.

39. Myers RP, Cerini R, Sayegh R, et al. Cardiac hepatopathy: clinical, hemodynamic, and histologic characteristics and correlations. Hepatology. 2003;37(2):393-400.

40. Moller S, Bernardi M. Interactions of the heart and the liver. Eur Heart J. 2013;34(36):2804-11.

41. Cleland JG, Carubelli V, Castiello T, et al. Renal dysfunction in acute and chronic heart failure: prevalence, incidence and prognosis. Heart Fail Rev. 2012;17(2):133-49.

42. Prasad PP, Yeh CM, Gurrieri P, et al. Pharmacokinetics of multiple doses of valsartan in patients with heart failure. J Cardiovasc Pharmacol. 2002;40(5):801-7.

43. Prasad P, Kalbag J, Hester A. Assessment of dose proportionality of an angiotensin II receptor blocker, valsartan, following single doses of 80,160 and $320 \mathrm{mg}$ to healthy subjects (abstract). Pharm Sci. 1998;S144.

44. Ayalasomayajula SP, Langenickel TH, Jordaan P, et al. Effect of renal function on the pharmacokinetics of LCZ696 (sacubitril/valsartan), an angiotensin receptor neprilysin inhibitor. Eur J Clin Pharmacol. 2016;72:1065-73.

45. Kulmatycki K, Langenickel T, Ng D, et al. Pharmacokinetics of single-dose LCZ696 in subjects with mild and moderate hepatic impairment. Clin Pharmacol Drug Dev. 2014;3(Suppl. 1):21.

46. Writing Committee Members. ACC/AHA Task Force members. ACC/AHA/HFSA focused update on new pharmacological therapy for heart failure: an update of the 2013 ACCF/AHA guideline for the management of heart failure: a report of the American College of Cardiology/American Heart Association Task Force on clinical practice guidelines and the Heart Failure Society of America. J Card Fail. 2016;22(9):659-69.

47. Ayalasomayajula S, Langenikel T, Malcolm K, et al. In vitro and clinical evaluation of OATP-mediated drug interaction potential of sacubitril/valsartan (LCZ696). J Clin Pharm Ther. 2016;41:424-31.

48. Hsiao HL, Langenickel TH, Greeley M, et al. Pharmacokinetic drug-drug interaction assessment between LCZ696, an angiotensin receptor neprilysin inhibitor, and hydrochlorothiazide, amlodipine, or carvedilol. Clin Pharmacol Drug Dev. 2015;4(6):407-17.

49. Gan L, Jiang X, Mendonza A, et al. Pharmacokinetic drug-drug interaction assessment of LCZ696 (an angiotensin receptor neprilysin inhibitor) with omeprazole, metformin or levonorgestrel-ethinyl estradiol in healthy subjects. Clin Pharmacol Drug Develop. 2015;5:27-39.

50. Tenero D, Boike S, Boyle D, et al. Steady-state pharmacokinetics of carvedilol and its enantiomers in patients with congestive heart failure. J Clin Pharmacol. 2000;40(8):844-53.

51. Oldham HG, Clarke SE. In vitro identification of the human cytochrome P450 enzymes involved in the metabolism of R(+)and S(-)-carvedilol. Drug Metab Dispos. 1997;25(8):970-7.

52. Bachmakov I, Werner U, Endress B, et al. Characterization of beta-adrenoceptor antagonists as substrates and inhibitors of the drug transporter P-glycoprotein. Fundam Clin Pharmacol. 2006;20(3):273-82.

53. Packer M, Fowler MB, Roecker EB, et al. Effect of carvedilol on the morbidity of patients with severe chronic heart failure: results of the carvedilol prospective randomized cumulative survival (COPERNICUS) study. Circulation. 2002;106(17):2194-9.

54. Budzynski J, Pulkowski G, Suppan K, et al. Improvement in health-related quality of life after therapy with omeprazole in patients with coronary artery disease and recurrent angina-like chest pain: a double-blind, placebo-controlled trial of the SF-36 survey. Health Qual Life Outcomes. 2011;9:77. 
55. Ogawa R, Echizen H. Drug-drug interaction profiles of proton pump inhibitors. Clin Pharmacokinet. 2010;49(8):509-33.

56. Shi S, Klotz U. Proton pump inhibitors: an update of their clinical use and pharmacokinetics. Eur J Clin Pharmacol. 2008;64(10):935-51.

57. Saydam M, Takka S. Bioavailability file: valsartan. FABAD J Pharm Sci. 2007;32:185-96.

58. Hirsh J. Oral anticoagulant drugs. $N$ Engl J Med. 1991;324(26):1865-75.

59. Black DJ, Kunze KL, Wienkers LC, et al. Warfarin-fluconazole II. A metabolically based drug interaction: in vivo studies. Drug Metab Dispos. 1996;24(4):422-8.

60. Wittkowsky AK. Warfarin and other coumarin derivatives: pharmacokinetics, pharmacodynamics, and drug interactions. Semin Vasc Med. 2003;3(3):221-30.

61. Serlin MJ, Breckenridge AM. Drug interactions with warfarin. Drugs. 1983;25(6):610-20.

62. National Cholesterol Education Program Expert Panel on Detection E, Treatment of high blood cholesterol in A. Third report of the national cholesterol education program (NCEP) expert panel on detection, evaluation, and treatment of high blood cholesterol in adults (adult treatment panel III): final report. Circulation. 2002;106(25):3143-421.

63. European Association for Cardiovascular Prevention and Rehabilitation, Reiner Z, Catapano AL, De Backer G, et al. ESC/EAS guidelines for the management of dyslipidaemias: the Task Force for the management of dyslipidaemias of the European Society of Cardiology (ESC) and the European Atherosclerosis Society (EAS). Eur Heart J. 2011;32(14):1769-818.

64. McMurray JJ, Packer M, Desai AS, et al. Baseline characteristics and treatment of patients in prospective comparison of ARNI with ACEI to determine impact on global mortality and morbidity in heart failure trial (PARADIGM-HF). Eur J Heart Fail. 2014;16(7):817-25.

65. Kalliokoski A, Niemi M. Impact of OATP transporters on pharmacokinetics. Br J Pharmacol. 2009;158(3):693-705.

66. Niemi M. Role of OATP transporters in the disposition of drugs. Pharmacogenomics. 2007;8(7):787-802.

67. Kindla J, Fromm MF, Konig J. In vitro evidence for the role of OATP and OCT uptake transporters in drug-drug interactions. Expert Opin Drug Metab Toxicol. 2009;5(5):489-500.

68. Higgins JW, Bao JQ, Ke AB, et al. Utility of Oatp1a/1b-knockout and OATP1B1/3-humanized mice in the study of OATP-mediated pharmacokinetics and tissue distribution: case studies with pravastatin, atorvastatin, simvastatin, and carboxydichlorofluorescein. Drug Metab Dispos. 2014;42(1):182-92.

69. Kunze A, Huwyler J, Camenisch G, et al. Prediction of organic anion-transporting polypeptide 1B1- and 1B3-mediated hepatic uptake of statins based on transporter protein expression and activity data. Drug Metab Dispos. 2014;42(9):1514-21.

70. Neuvonen PJ, Niemi M, Backman JT. Drug interactions with lipid-lowering drugs: mechanisms and clinical relevance. Clin Pharmacol Ther. 2006;80(6):565-81.

71. Vallon V, Rieg T, Ahn SY, et al. Overlapping in vitro and in vivo specificities of the organic anion transporters OAT1 and OAT3 for loop and thiazide diuretics. Am J Physiol Renal Physiol. 2008;294(4):F867-73.

72. Yamashiro W, Maeda K, Hirouchi M, et al. Involvement of transporters in the hepatic uptake and biliary excretion of valsartan, a selective antagonist of the angiotensin II AT1-receptor, in humans. Drug Metab Dispos. 2006;34(7):1247-54.

73. Ponto LL, Schoenwald RD. Furosemide (frusemide): a pharmacokinetic/pharmacodynamic review (Part I). Clin Pharmacokinet. 1990;18(5):381-408.
74. Bindschedler M, Degen P, Flesch G, et al. Pharmacokinetic and pharmacodynamic interaction of single oral doses of valsartan and furosemide. Eur J Clin Pharmacol. 1997;52(5):371-8.

75. Eichhorn EJ, Gheorghiade M. Digoxin. Prog Cardiovasc Dis. 2002;44(4):251-66.

76. Gheorghiade M, van Veldhuisen DJ, Colucci WS. Contemporary use of digoxin in the management of cardiovascular disorders. Circulation. 2006;113(21):2556-64.

77. de Lannoy IA, Silverman M. The MDR1 gene product, P-glycoprotein, mediates the transport of the cardiac glycoside, digoxin. Biochem Biophys Res Commun. 1992;189(1):551-7.

78. Hori R, Okamura N, Aiba T, et al. Role of P-glycoprotein in renal tubular secretion of digoxin in the isolated perfused rat kidney. J Pharmacol Exp Ther. 1993;266(3):1620-5.

79. Wessler JD, Grip LT, Mendell J, et al. The P-glycoprotein transport system and cardiovascular drugs. J Am Coll Cardiol. 2013;61(25):2495-502.

80. Hill NS, Antman EM, Green LH, et al. Intravenous nitroglycerin: a review of pharmacology, indications, therapeutic effects and complications. Chest. 1981;79(1):69-76.

81. Nichols DJ, Muirhead GJ, Harness JA. Pharmacokinetics of sildenafil after single oral doses in healthy male subjects: absolute bioavailability, food effects and dose proportionality. Br J Clin Pharmacol. 2002;53(Suppl. 1):5S-12S.

82. Mancia G, Fagard R, Narkiewicz K, et al. 2013 ESH/ESC guidelines for the management of arterial hypertension: the Task Force for the management of arterial hypertension of the European Society of Hypertension (ESH) and of the European Society of Cardiology (ESC). J Hypertens. 2013;31(7):1281-357.

83. Niemeyer C, Hasenfuss G, Wais U, et al. Pharmacokinetics of hydrochlorothiazide in relation to renal function. Eur $\mathrm{J}$ Clin Pharmacol. 1983;24(5):661-5.

84. Beermann B, Groschinsky-Grind M, Rosen A. Absorption, metabolism, and excretion of hydrochlorothiazide. Clin Pharmacol Ther. 1976;19(5 Pt 1):531-7.

85. Chung N, Baek S, Chen MF, et al. Expert recommendations on the challenges of hypertension in Asia. Int $\mathrm{J}$ Clin Pract. 2008;62(9):1306-12.

86. Wang JG, Kario K, Lau T, et al. Use of dihydropyridine calcium channel blockers in the management of hypertension in Eastern Asians: a scientific statement from the Asian Pacific Heart Association. Hypertens Res. 2011;34(4):423-30.

87. Wang JG, Li Y. Characteristics of hypertension in Chinese and their relevance for the choice of antihypertensive drugs. Diabetes Metab Res. 2012;28:67-72.

88. Ogihara T, Kikuchi K, Matsuoka H, et al. The Japanese Society of Hypertension guidelines for the management of hypertension (JSH 2009). Hypertens Res. 2009;32(1):3-107.

89. Zhu Y, Wang F, Li Q, et al. Amlodipine metabolism in human liver microsomes and roles of CYP3A4/5 in the dihydropyridine dehydrogenation. Drug Metab Dispos. 2014;42(2):245-9.

90. Zhang H, Cui D, Wang B, et al. Pharmacokinetic drug interactions involving 17alpha-ethinylestradiol: a new look at an old drug. Clin Pharmacokinet. 2007;46(2):133-57.

91. Moreno I, Quinones L, Catalan J, et al. Influence of CYP3A4/5 polymorphisms in the pharmacokinetics of levonorgestrel: a pilot study [in Spanish]. Biomedica. 2012;32(4):570-7.

92. Rakugi H, Kario K, Yamaguchi M, et al. Efficacy and safety of LCZ696 compared with olmesartan in Japanese patients with systolic hypertension. Hypertens. 2014;64:A474.

93. Ito S, Satoh M, Tamaki Y, et al. Safety and efficacy of LCZ696, a first-in-class angiotensin receptor neprilysin inhibitor, in Japanese patients with hypertension and renal dysfunction. Hypertens Res. 2015;38(4):269-75. 
94. Gan L, Langenickel T, Petruck J, et al. Effects of age and sex on the pharmacokinetics of LCZ696, an angiotensin receptor neprilysin inhibitor. J Clin Pharmacol. 2016;56(1):78-86.

95. Jhund PS, Fu M, Bayram E, et al. Efficacy and safety of LCZ696 (sacubitril-valsartan) according to age: insights from PARADIGM-HF. Eur Heart J. 2015;36(38):2576-84.

96. Marsh S, Xiao M, Yu J, et al. Pharmacogenomic assessment of carboxylesterases 1 and 2. Genomics. 2004;84(4):661-8.

97. Suzaki Y, Uemura N, Takada M, et al. The effect of carboxylesterase 1 (CES1) polymorphisms on the pharmacokinetics of oseltamivir in humans. Eur $\mathrm{J}$ Clin Pharmacol. 2013;69(1):21-30.

98. Levey AS, Bosch JP, Lewis JB, et al. A more accurate method to estimate glomerular filtration rate from serum creatinine: a new prediction equation. Modification of Diet in Renal Disease Study Group. Ann Intern Med. 1999;130(6):461-70.

99. Brookman LJ, Rolan PE, Benjamin IS, et al. Pharmacokinetics of valsartan in patients with liver disease. Clin Pharmacol Ther. 1997;62(3):272-8.

100. Han Y, Ayalasomayajula S, Pan W, et al. Pharmacokinetic, safety and tolerability of sacubitril/valsartan (LCZ696) after single-dose administration in healthy Chinese subjects. Eur J Drug Metab Pharmacokinet. 2017;42(1):109-16.

101. Langenickel TH, Jordaan P, Petruck J, et al. Single therapeutic and supratherapeutic doses of sacubitril/valsartan (LCZ696) do not affect cardiac repolarization. Eur J Clin Pharmacol. 2016;72(8):917-24. 